Vol.16, No. 58, January, 2021, 185-202

\title{
JAUES
}

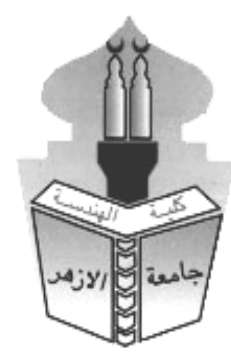

\section{CRITERIA FOR THE SUSTAINABLE DESIGN OF MUSEUM BUILDINGS AND ITS EFFECT ON FORMATION}

\author{
Aya Ashour*1 and Mohamed Seif Al Nasr ${ }^{2}$ \\ ${ }^{1}$ Demonstrator, architectural Department, Obour High Institute for engineering and \\ Technology, Cairo, Egypt. \\ ${ }^{2}$ Assistant Professor, Engineering Faculty, architectural Department, Helwan University. \\ Cairo, Egypt. \\ *Corresponding Author E-mail: architect.ayaa@gmail.com
}

\begin{abstract}
:
This research paper aims to study the impact of applying sustainability on museum buildings in different countries to find out what are the formal features of sustainable modern museum buildings, and how the application of sustainability criteria affects through the elements of formation in museum buildings, where we try to pose this problem by answering some of the questions that are raised and They are: What are the influences that affect the formation of museum buildings and what are the vocabulary of sustainable formation of modern museum buildings? The importance of studying the building is due to the fact that museums are cultural buildings that have a special character in terms of formation and size, so what the building represents in terms of history or a work of art in itself. The architect Richard Meier mentioned museum design among the most free experiences of expression, the formation of museum buildings. It has factors that affect it to bring it out in a final way that has a certain character. This image and the final shape have an impact on the user and affect him.
\end{abstract}

\section{KEYWORDS : Sustainable Museum Design, Museum Formation, Sustainable Criteria, Green Museum, Sustainable Criteria In Museum.}

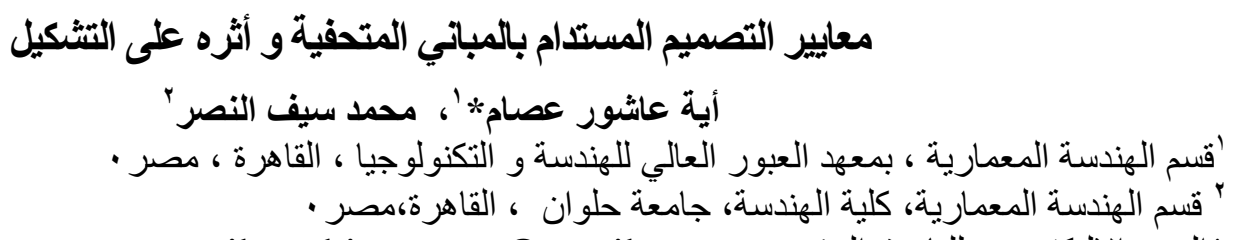

E-mail: architect.ayaa@gmail.com : البريد الاليكتروني للباحث الرئيسية

تهدف هذه الورقة البحثية لدراسة اثر تطبيق الاستدامة على المباني المتحفية بالدول المحتلفة لمعرفة ما هي السمات الثكلية

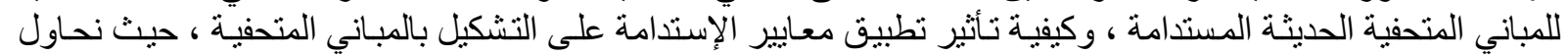

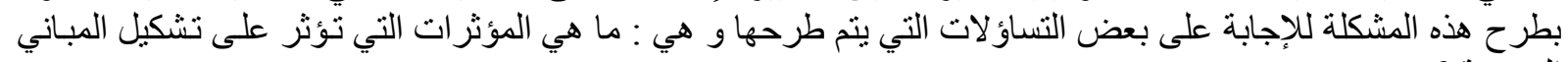

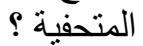

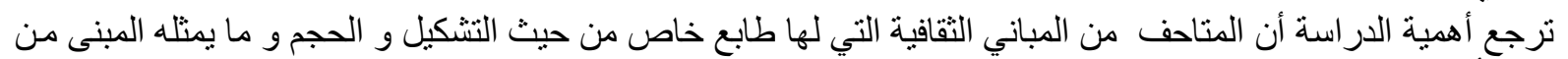

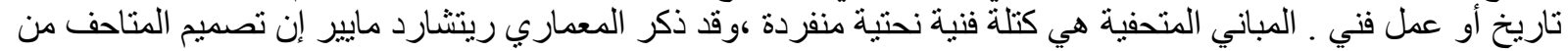

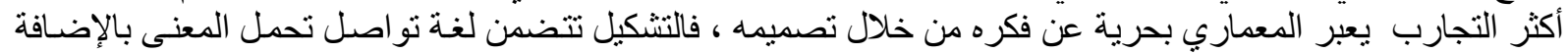
كونه يلعب دور وظيفي مهم . 
الكلمات المفتاحية : التصميم المستدام للمتاحف، تثكيل المتاحف، معايير الاستدامة، معايير الاستدامة بالمتاحف ، المتاحف الخضر اءو.

المقدمة : المقا

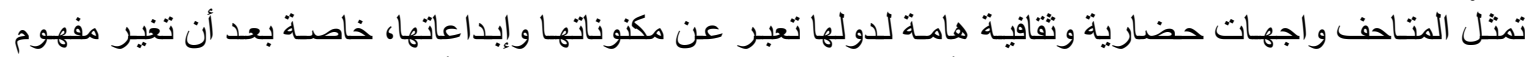

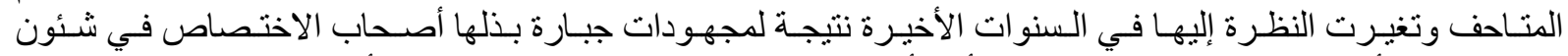

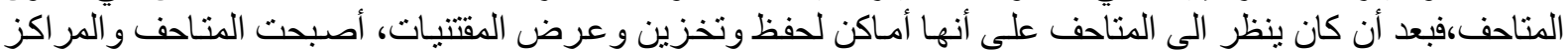

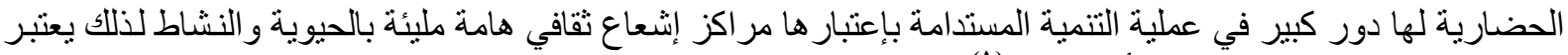

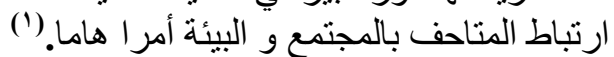

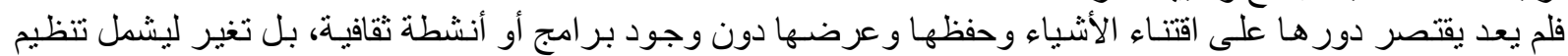

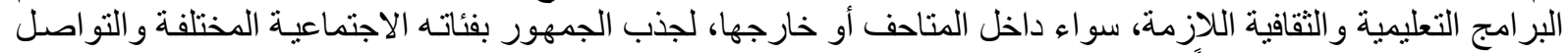

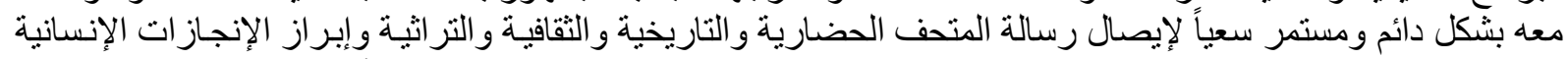

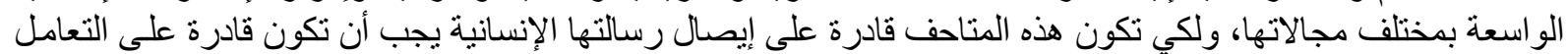

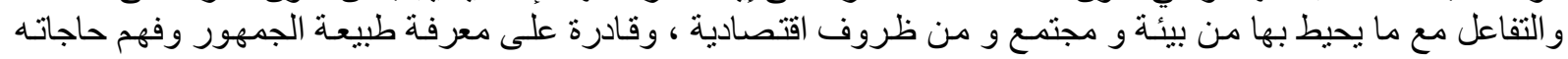

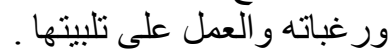

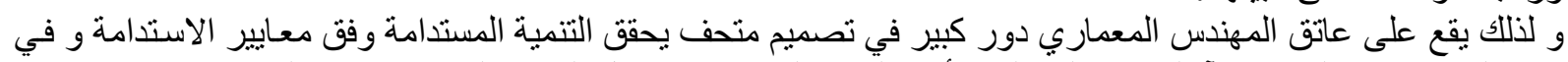

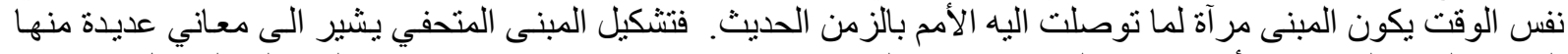

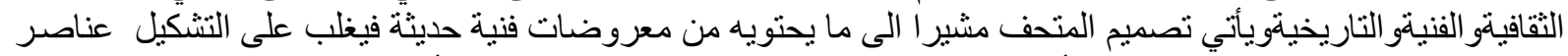

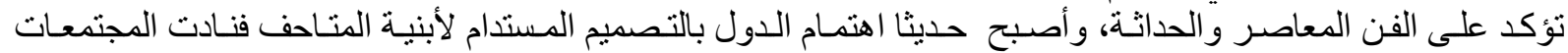

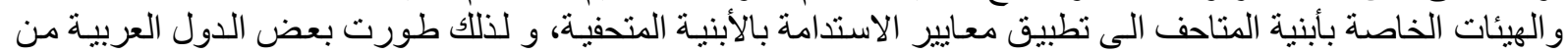

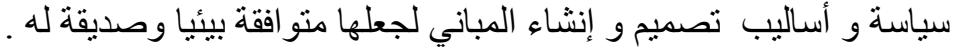

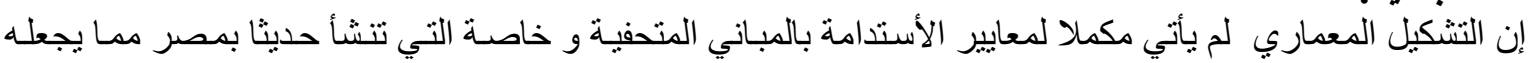

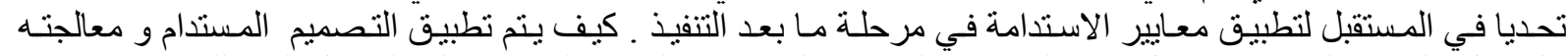

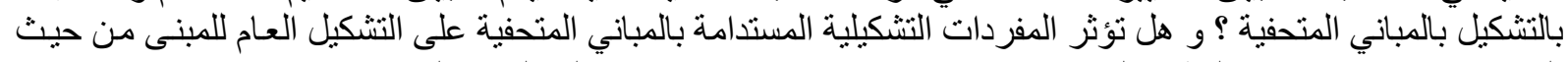
العناصر و نتجت عن هذا التطبيق لمعايير الاستدامة نتج عنه مفردات جديدة علي لئي المبنى المتحفي ؟

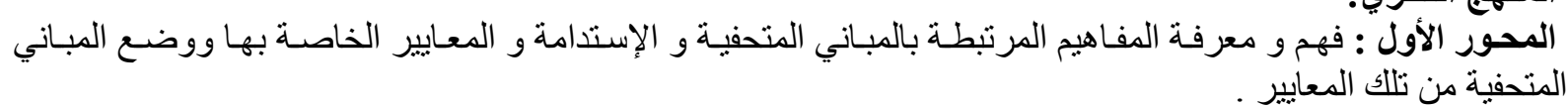

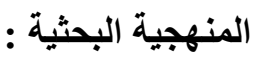
المنهج النظري: المنه:

المحور الثاني : التعرف على عناصر التشكيل و فهم ما هي المؤثرات التي تدخل على التثكيل و تؤثر بالمباني المتحفية

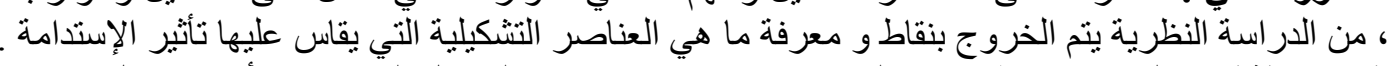
المحور الثالث : الخروج بنقاط رئيسية لمعايير الإستدامة و عناصر التشكيل المعماري نأثرت بشكل مبانشر بالإستدامة .

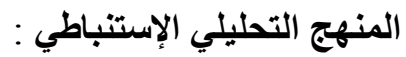

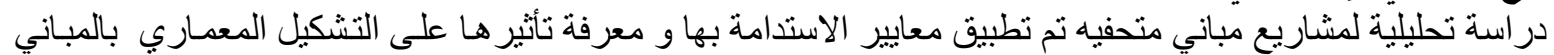

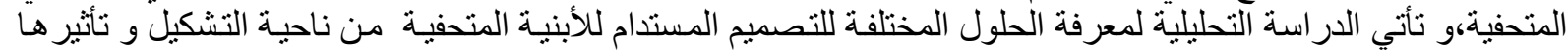

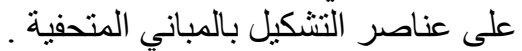

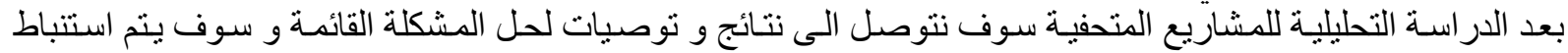

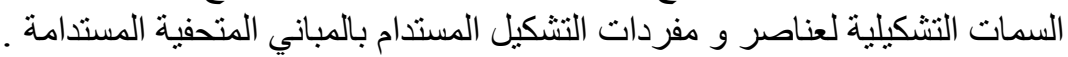

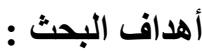

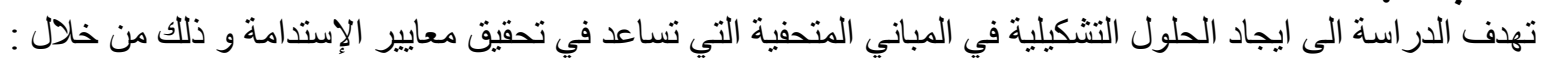

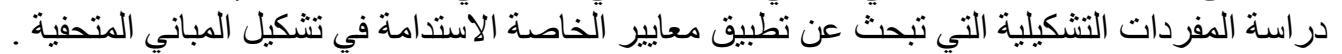

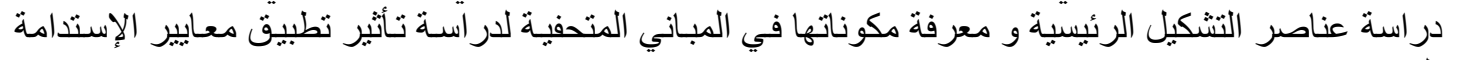
عليها . 


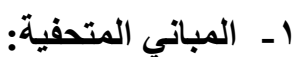

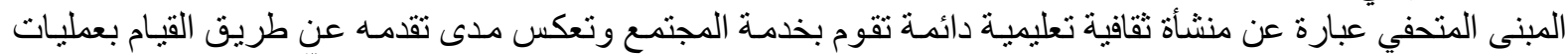

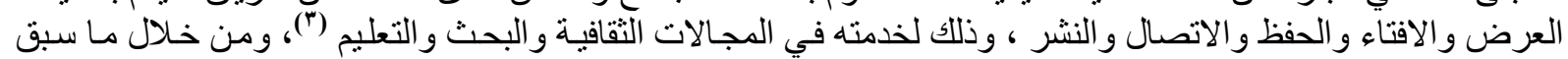

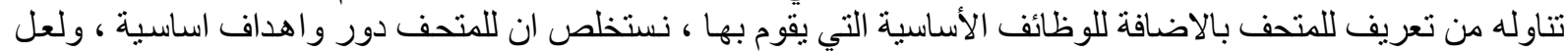

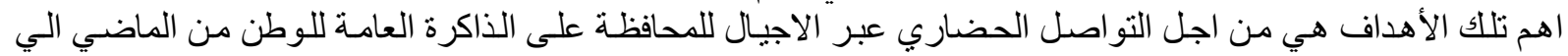

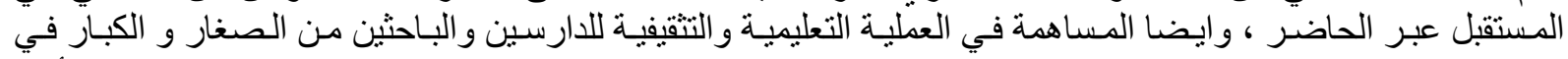

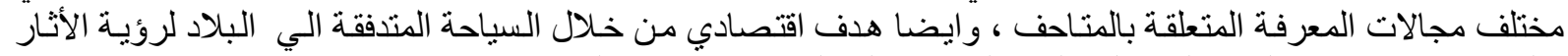

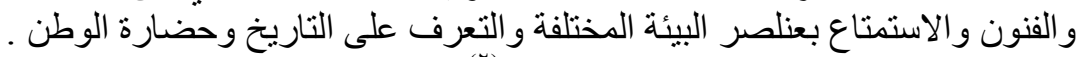

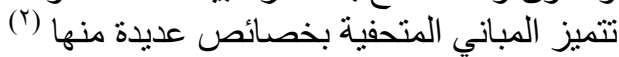

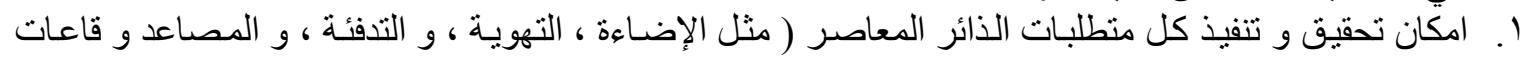

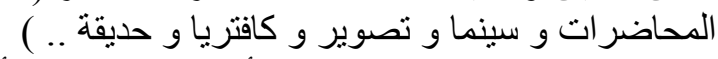

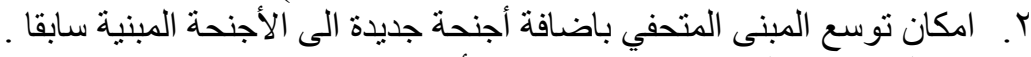

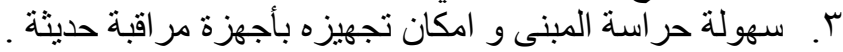

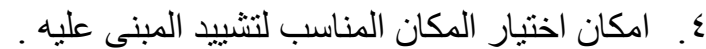
๑م. امكان تشييد مبان حديثة لمتاحف من شأنها ان تشكل عليه ( مدينة متحفية ) .
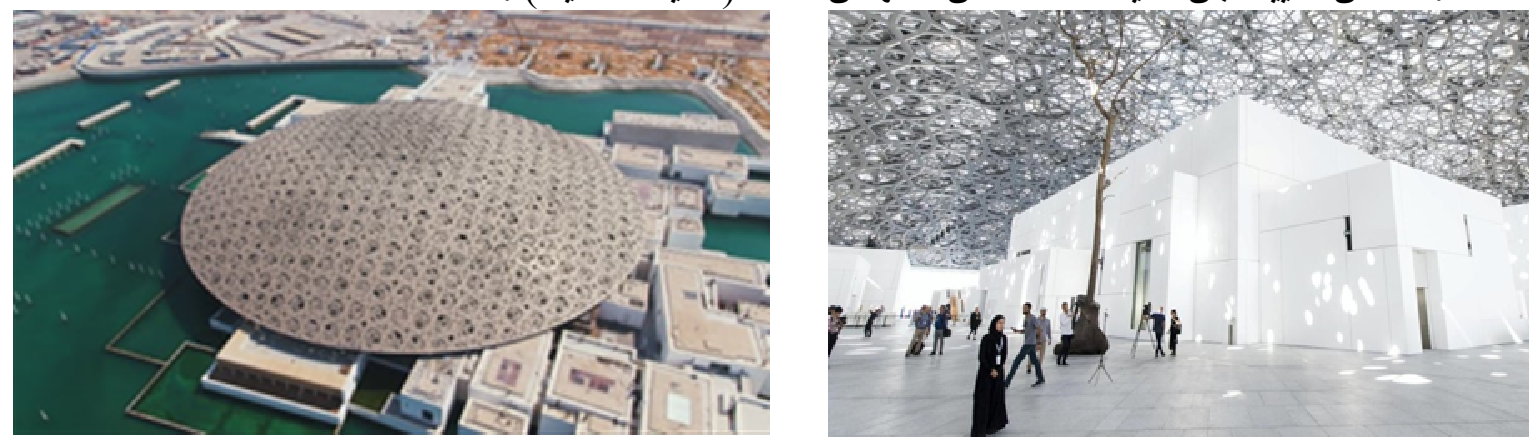

شكل (1) مبنى متحف اللوفر بأبوظبي

https://www.louvreabudhabi.ae/ar/about-us/architecture : المصدر

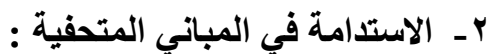

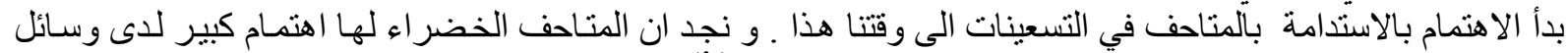

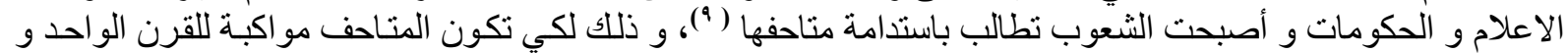

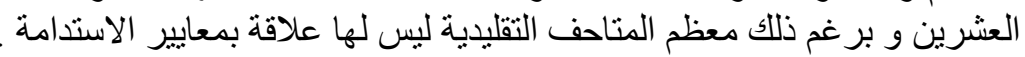

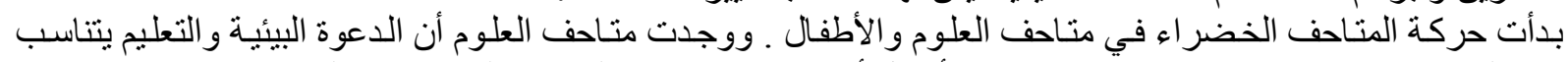

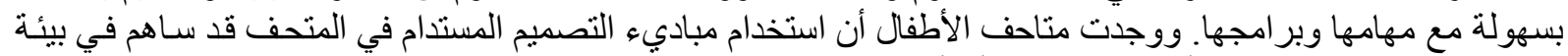

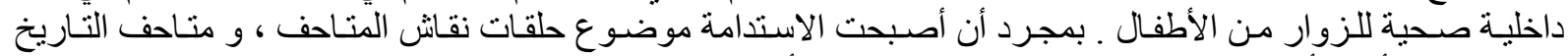
الطبيعي وجد أيضا أن من ضمن مهامهم الخاصة هي حفظ الأنو اع المهددة من الانقر اض و و تعتبر في جوهر هـا نشر للتعليم

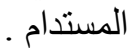

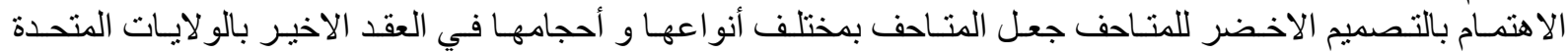

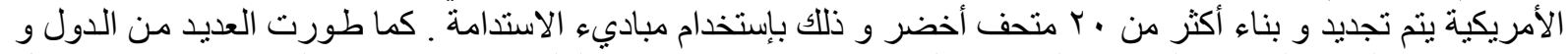

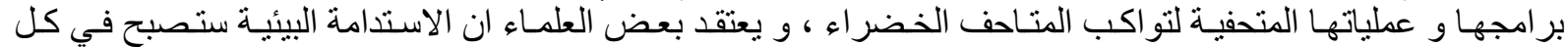
المتاحف في المستقبل (·) (1)

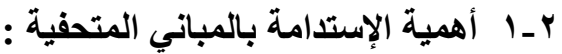

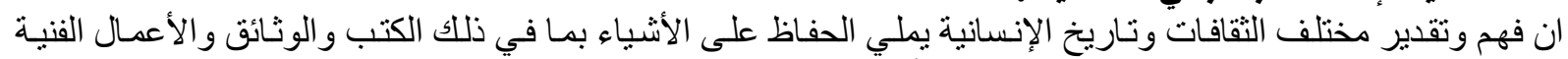

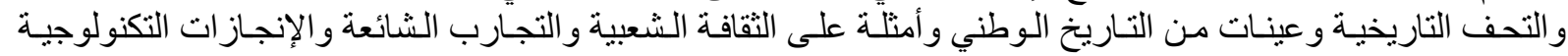

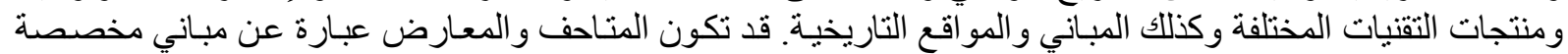




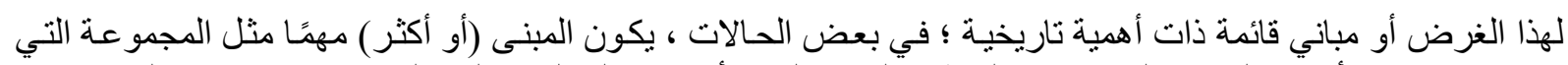

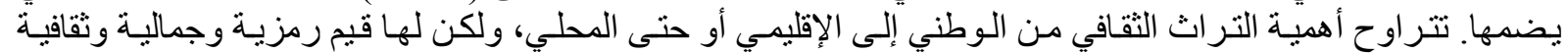

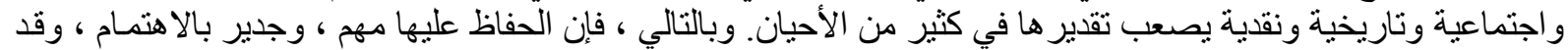

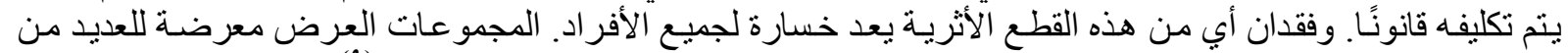

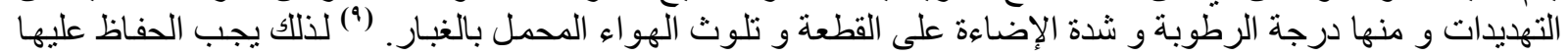

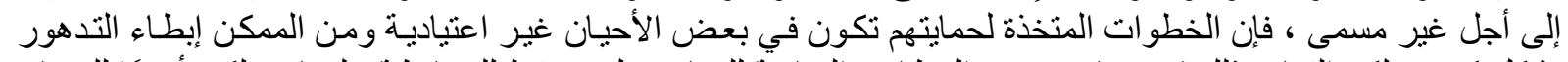

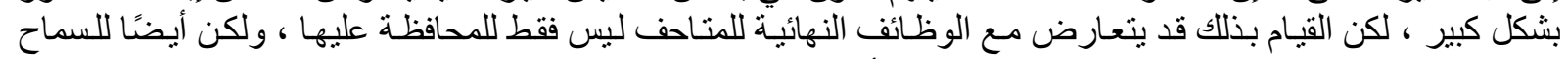

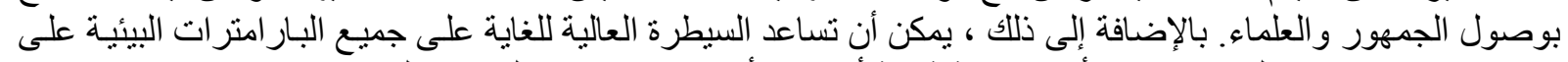

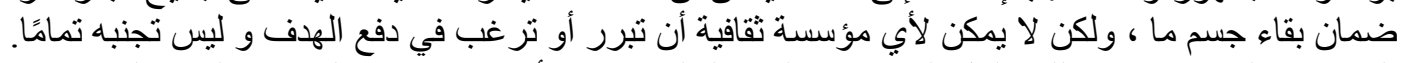

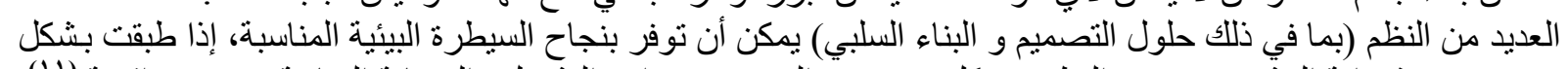

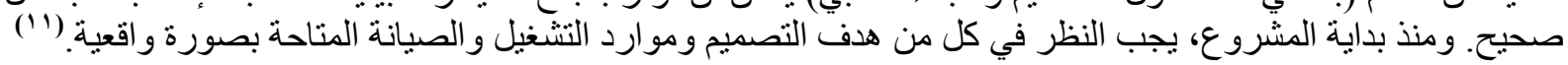

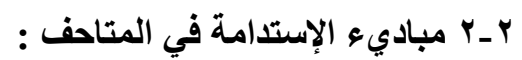

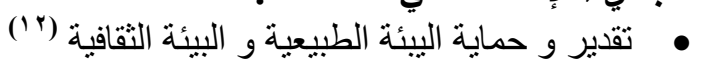

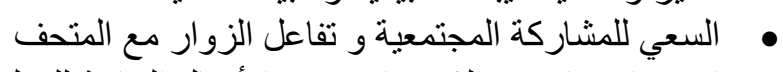

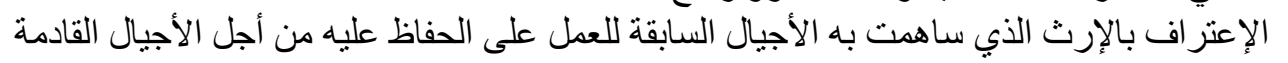

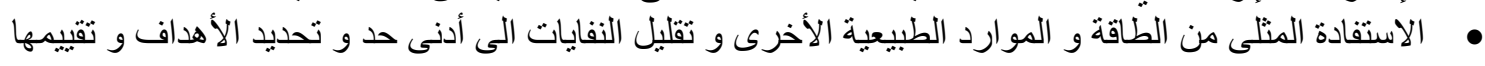

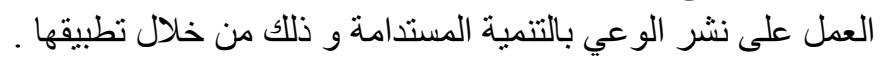

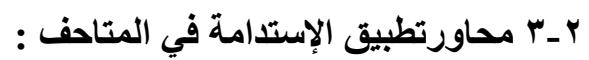

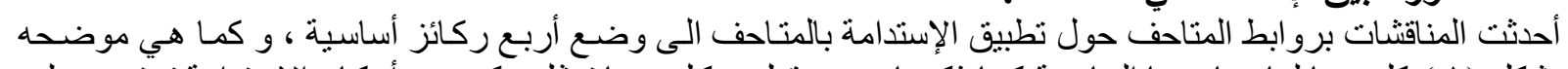

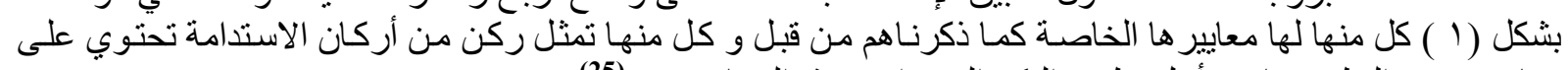

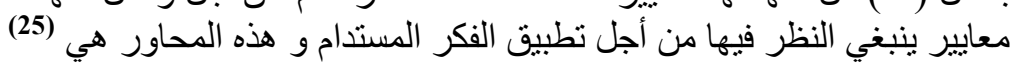
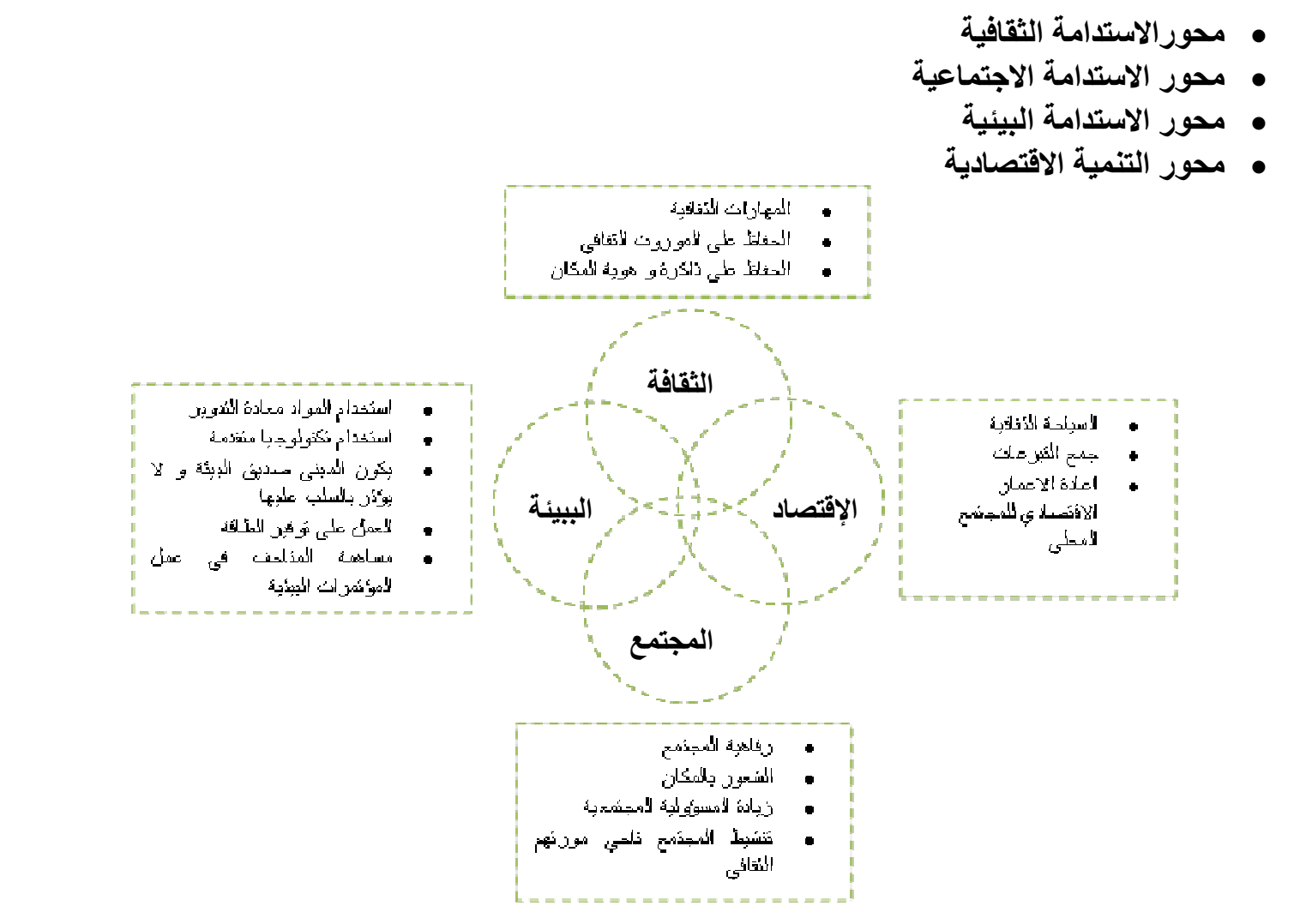

Lamberta, Boukasb, \& ) : شكل( () المحاور الأربعة للتمية المستدامة بالمتاحفة الثقافة و المجتمع و البيئة و الاقتصاد المصدر - (Yeralia, 2014, p. 570 


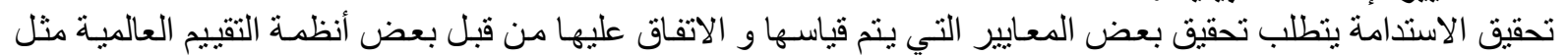

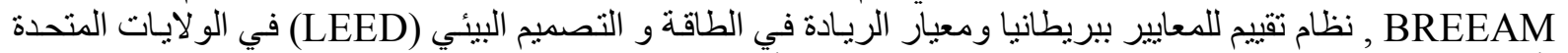

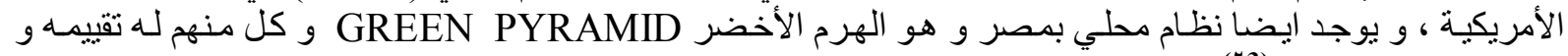

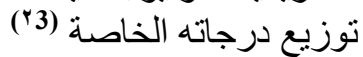

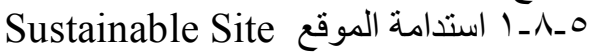

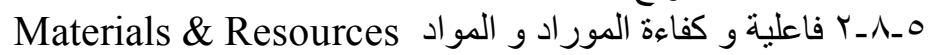

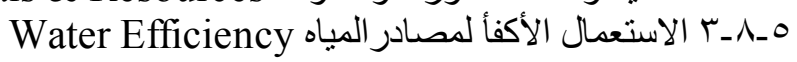

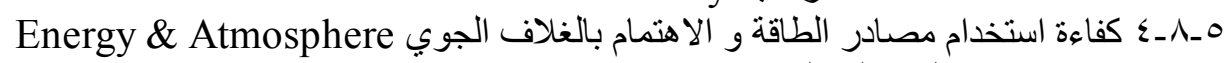

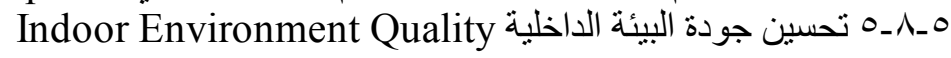

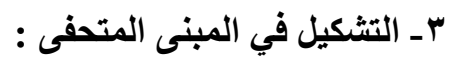

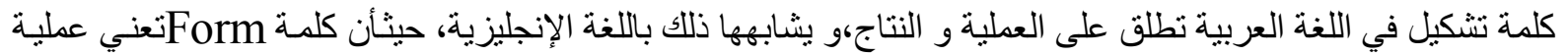

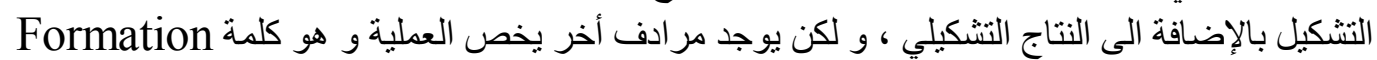

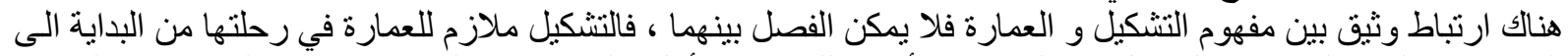

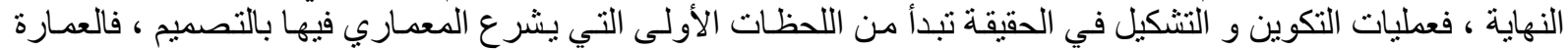

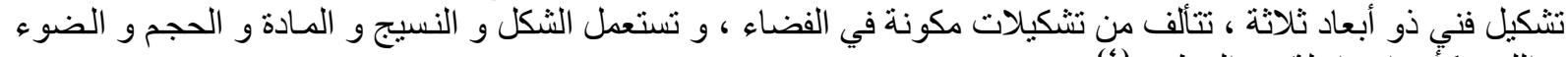

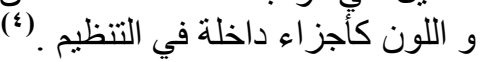

\section{بـ إصر التثكيل بالمباني المتحفية : عناصية}

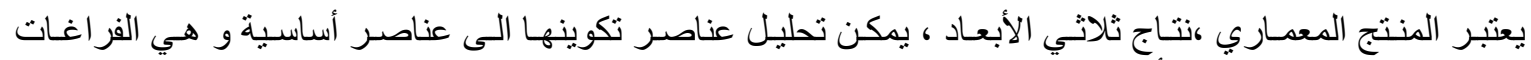

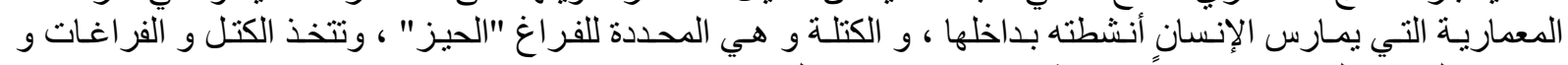

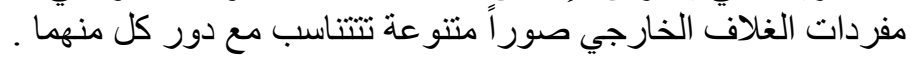

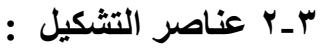

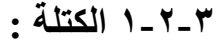

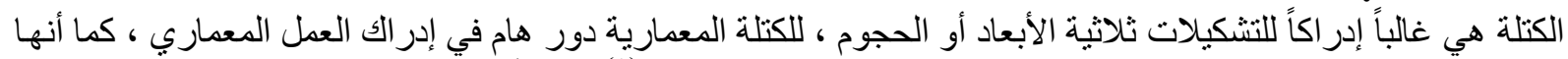

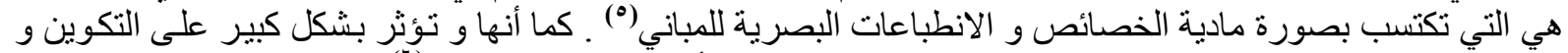

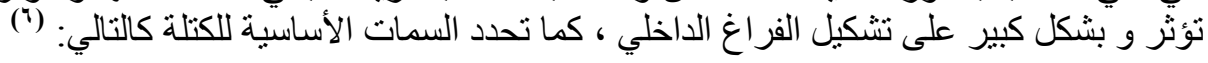

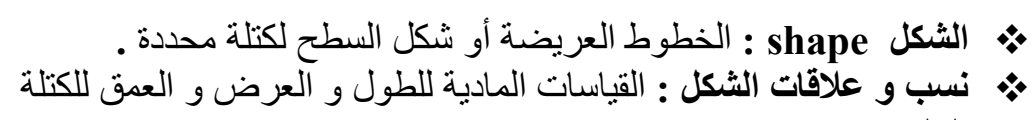

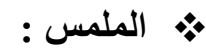
• الثفافية و المسامية : الثفافية هي الخاصية التي تسمح بمرور الضوء من خلال السطح بنسب متفاوتة ، المسامية

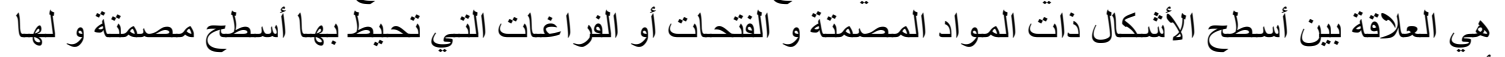

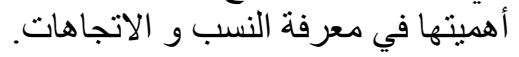
الإضاءة : فالقيمة الضوئية ما هي الا الضوء الضئه الرئيسي و درجاته المتفاوتة اعتمادا على شدة الضوء و زاوية الاسقاط (v) على الشكل

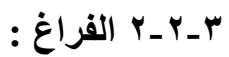

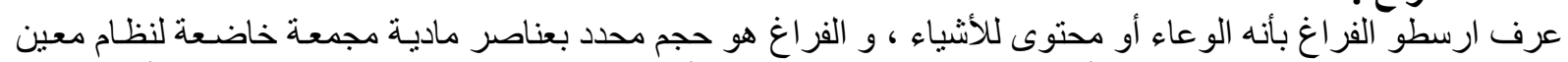

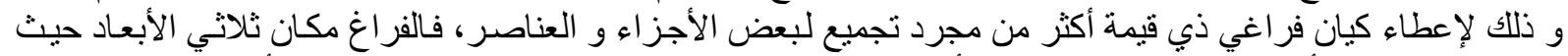

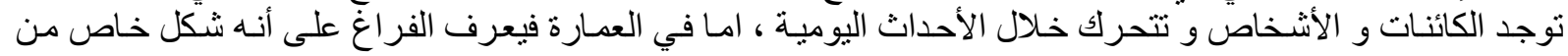

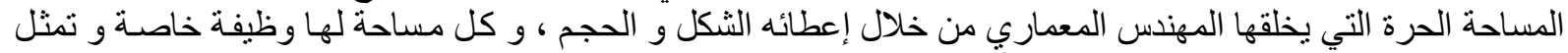

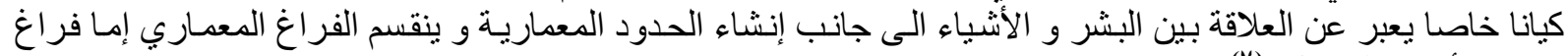




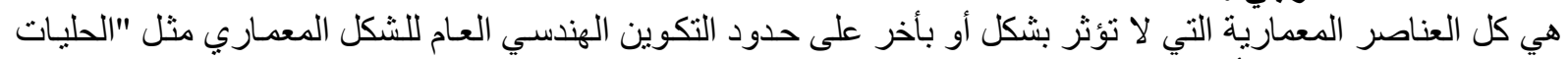

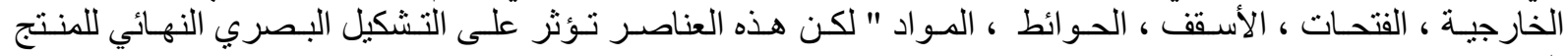

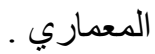

\section{r-r القوى المؤثرة على تشكيل المباني المتحفية:}

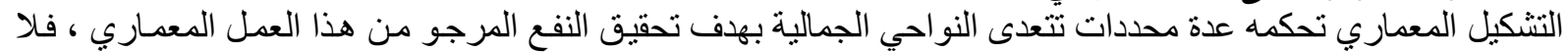

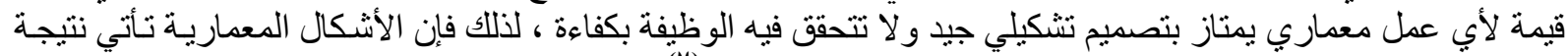

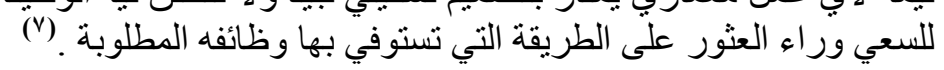

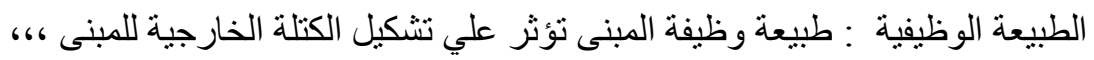

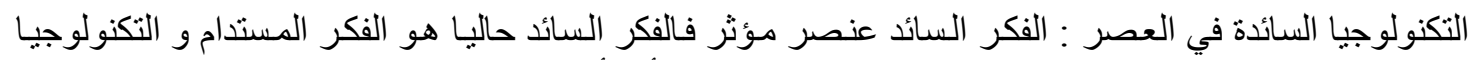

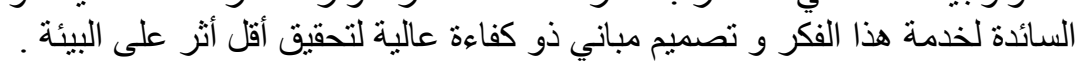

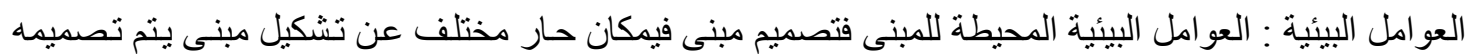

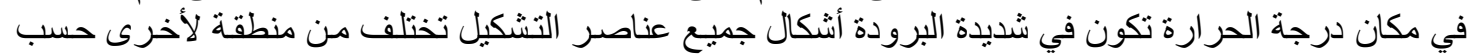
المحددات الطبيعية و البيئية ، ،

العوامل الاجتماعية : المقصود هنا العادات و التقاليد و ثنقافة الشعب نفسه مؤثر من المؤثرات القويـة على تشكيل

العوامل الجمالية : الجمال ينقسم الي عدة نواحي جمال فكري و جمال حسي و جمال رمزي ،و كل منهما لله سمة في التعبير من خلال التشكيل ، التمل ،

ع ـ علاقة التثكيل بالاستدامة في المباني المتحفية :

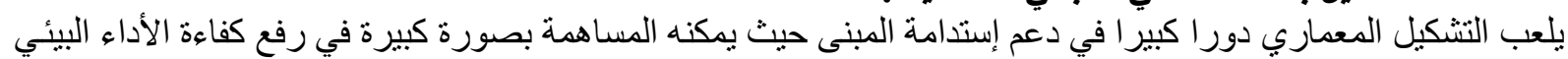

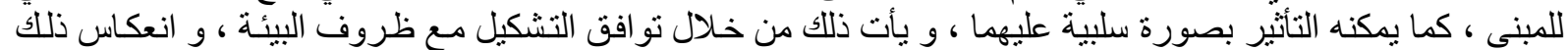

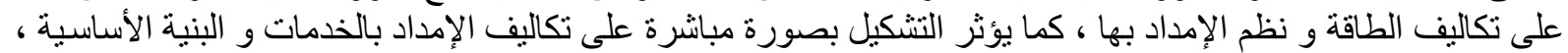

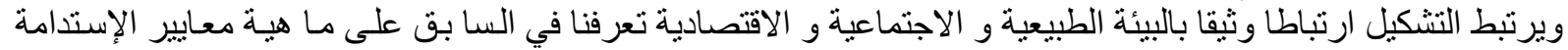

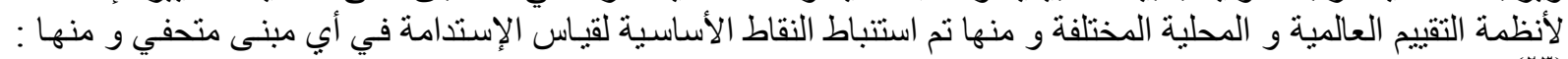

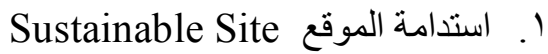

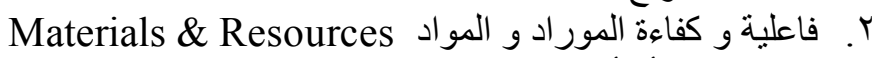

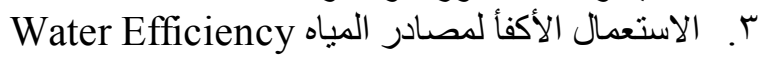

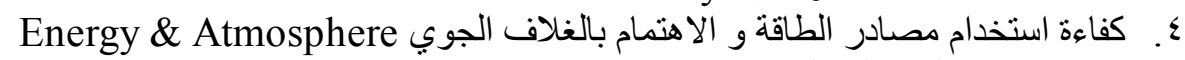

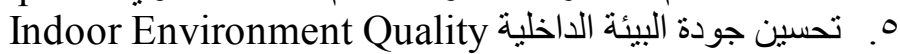
T. الابتكار في التصميم

و نم التعرف في السابق على عناصر التشكيل الرئيسية و منها :

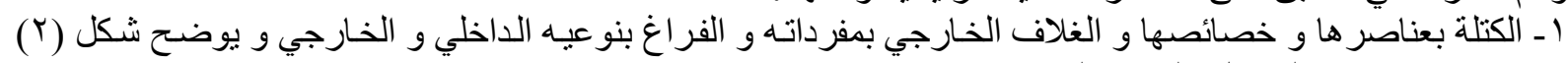
عناصر الاستدامة و التشكيل بالمباني المتحفية . 


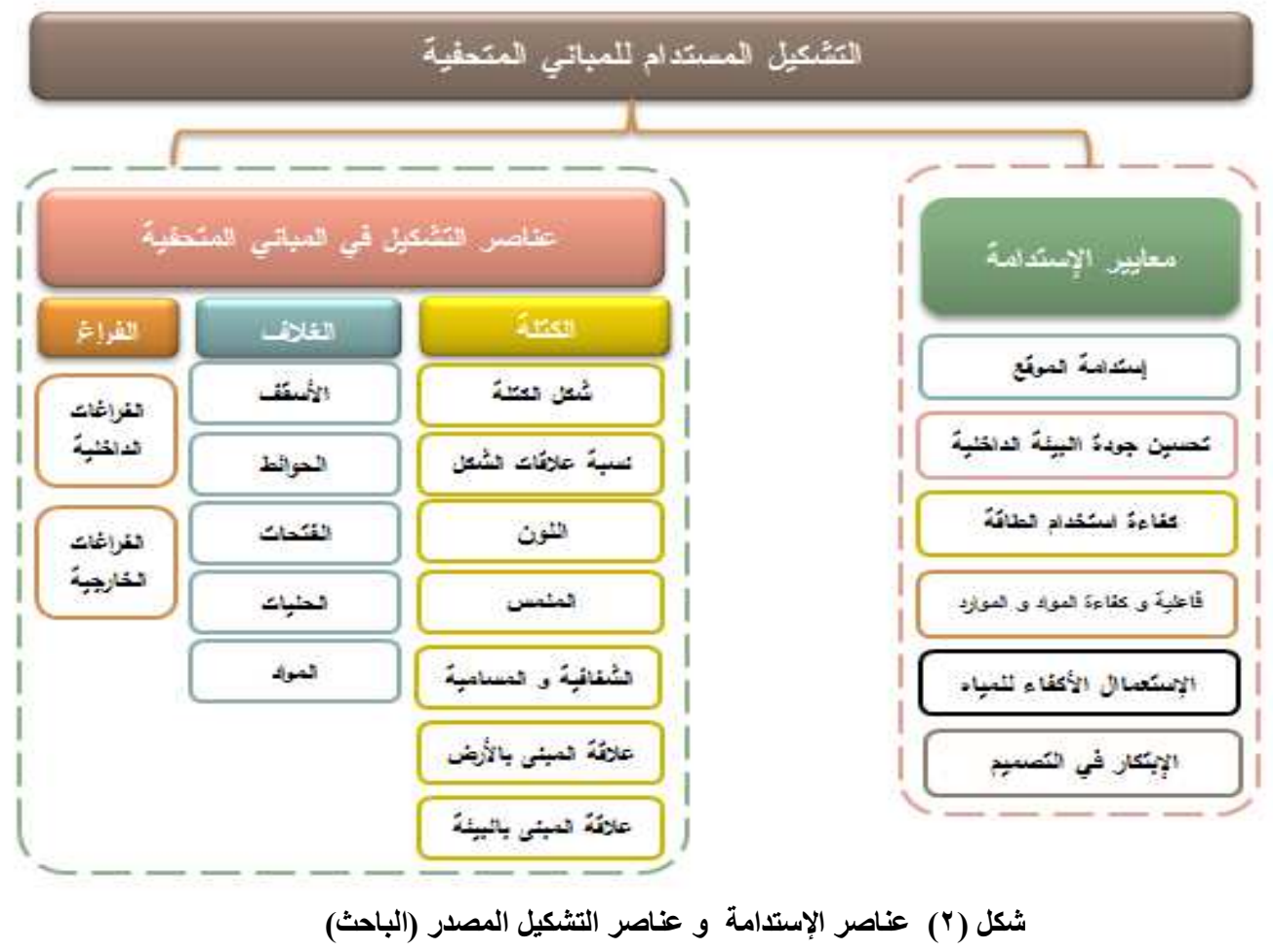

ع ــ المعيار استدامة الموقع و تثنكيل المباني المتحفية :

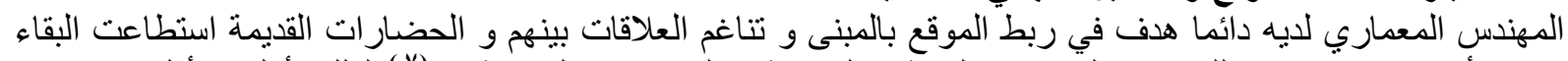

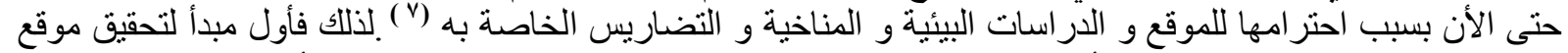

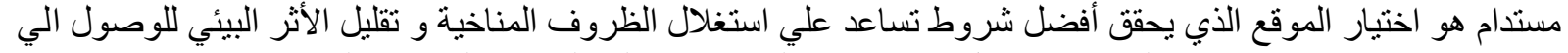

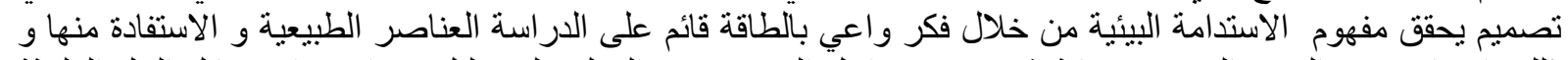

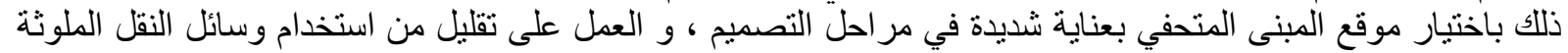

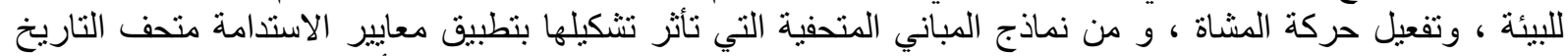

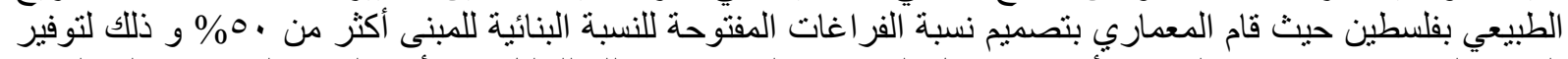

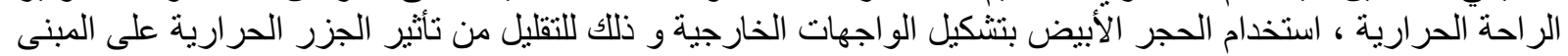

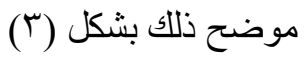

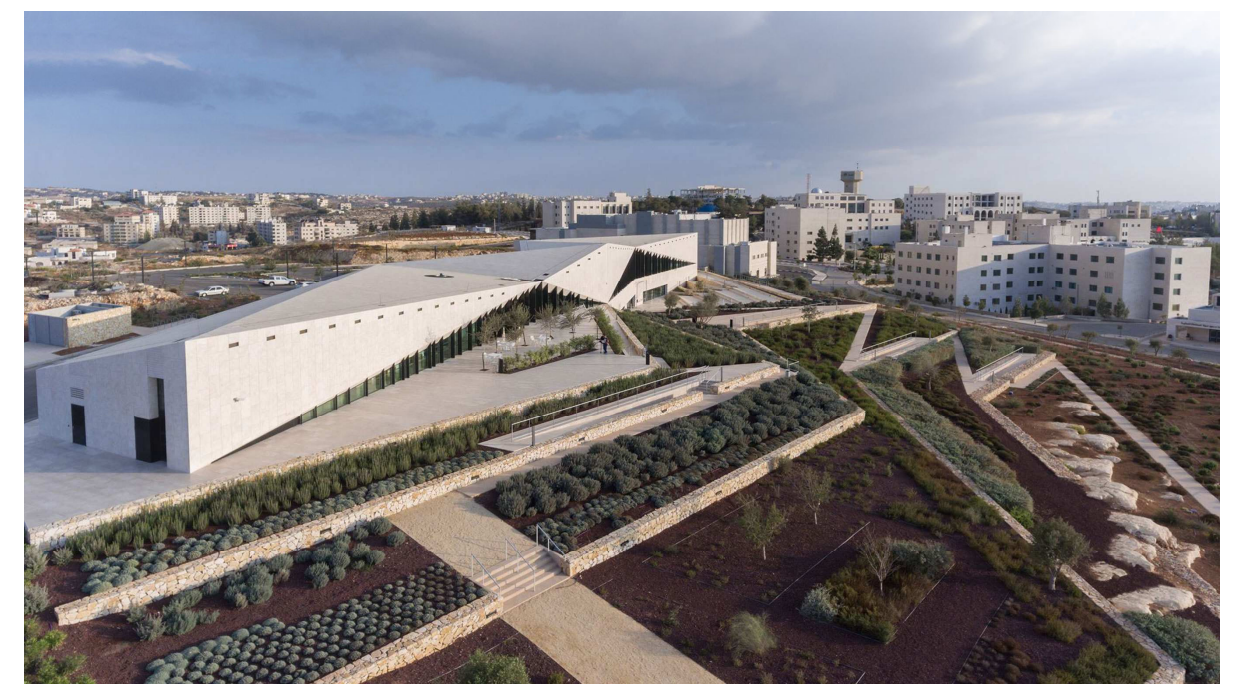

شكل ("آ) متحف التاريخ الطبيعي بفلسطين يوضح تأثير استدامة الموقع علي التثكيل بالمبنى المتحفي http://data.palmuseum.org/index.php/s/MsClQJSYAgUdRJQ\#pdfviewer : المصفي 


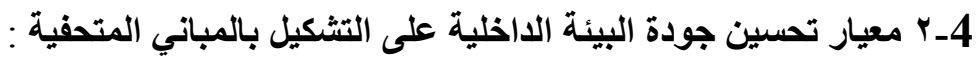

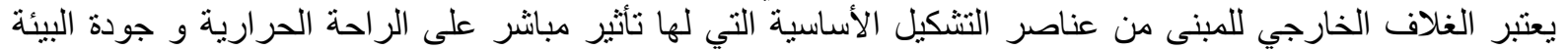

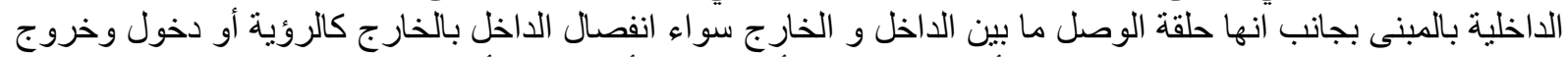

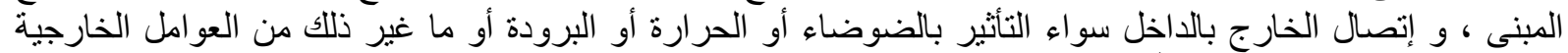

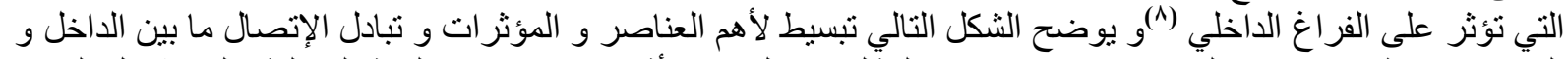

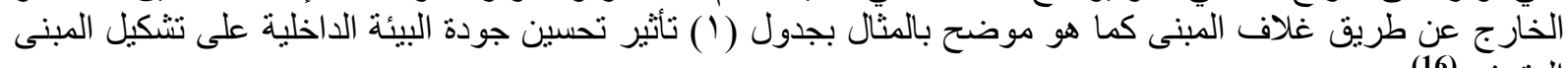

جدول (1) أثر تطبيق تحسين جودة البيئة الداخلية على عناصر التثكيل المعماري في المباني المتحفية المصدر الباحث

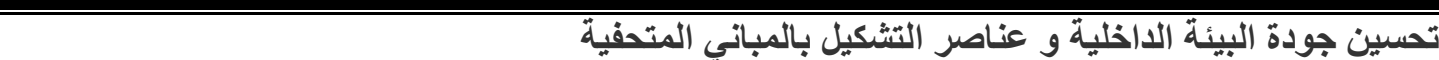

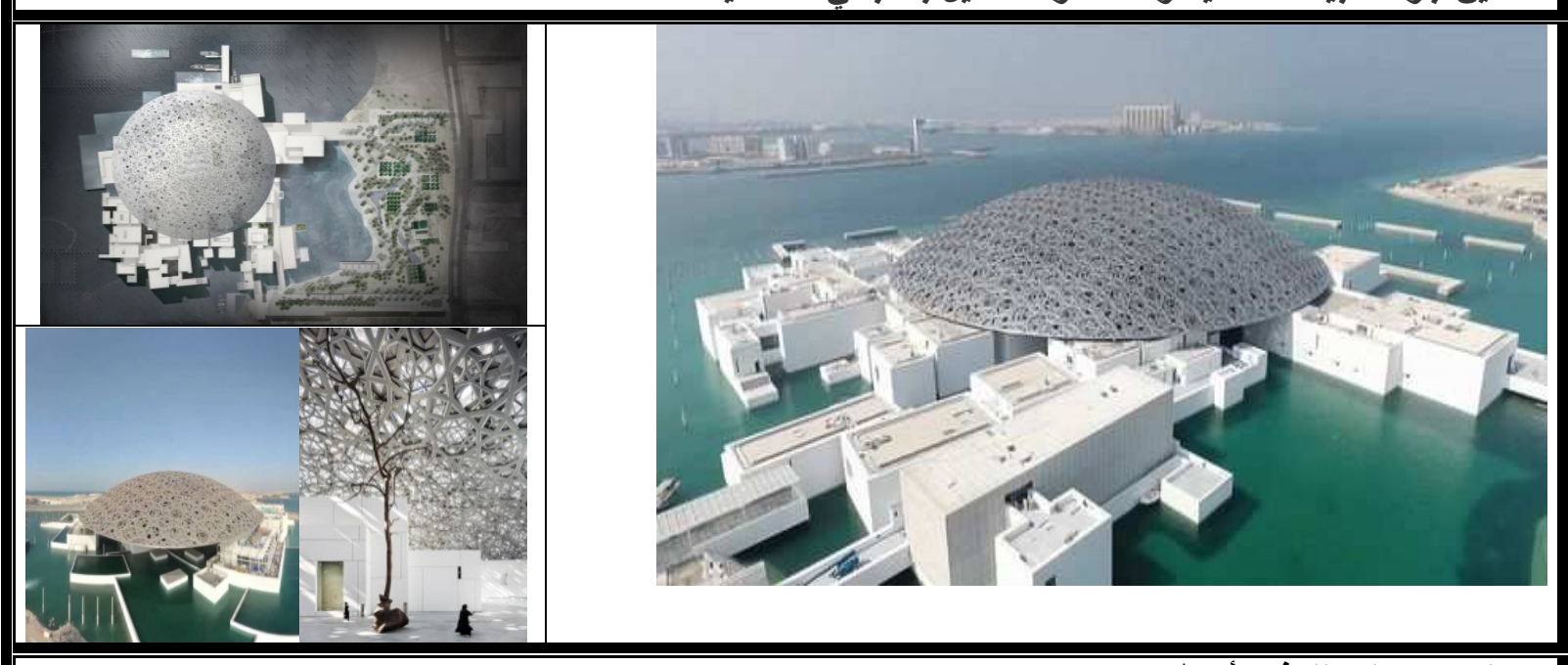

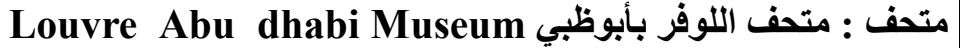

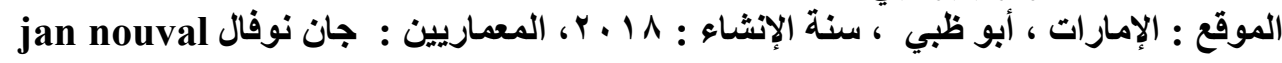

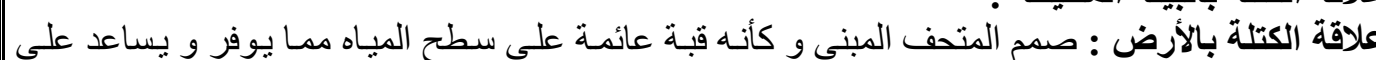

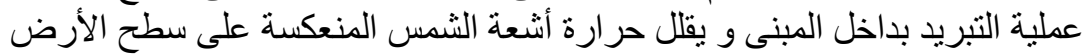

الإقف : شكل سقف المبنى على شكل القبة بفصل الساحة الخارجية عن حرارة الشُمس بالإضافة الى توفير

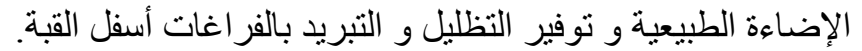

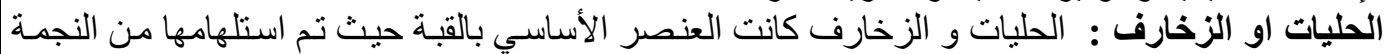

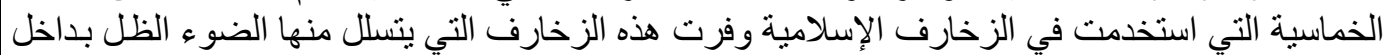

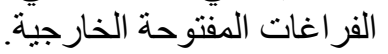

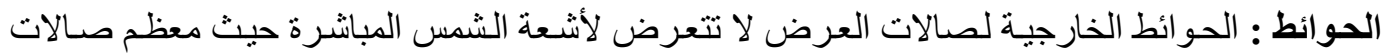

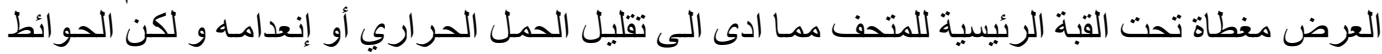

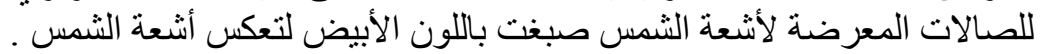

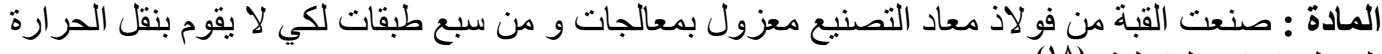

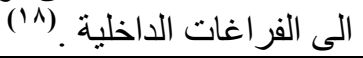

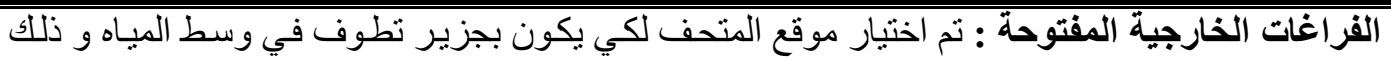

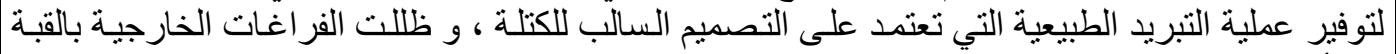

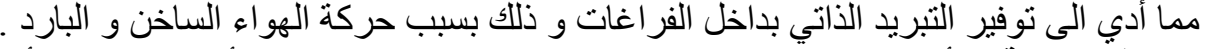

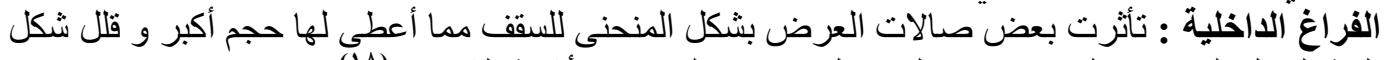

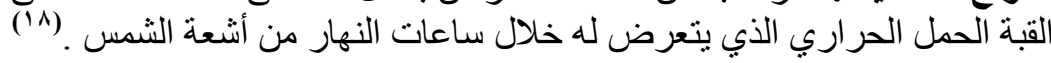


ع ــ تأثير معيار الحفاظ على الطاقة في تثكيل المباني المتحفية :

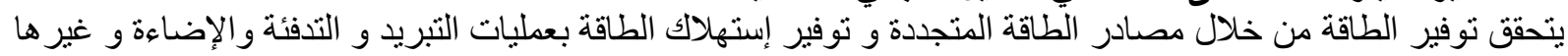

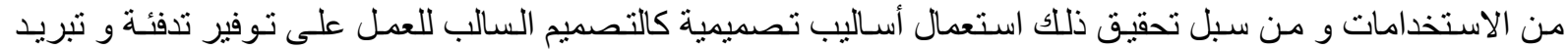

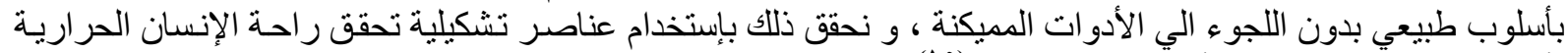

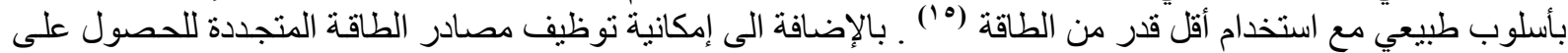

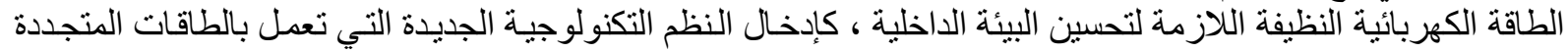

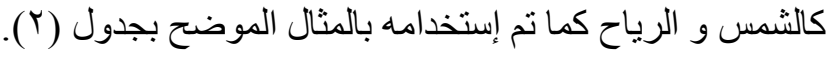

جدول (r) أثر تطبيق معيار حفظ الطاقة على عناصر التثكيل المعماري في المباني المتحفية المصدر الباحث

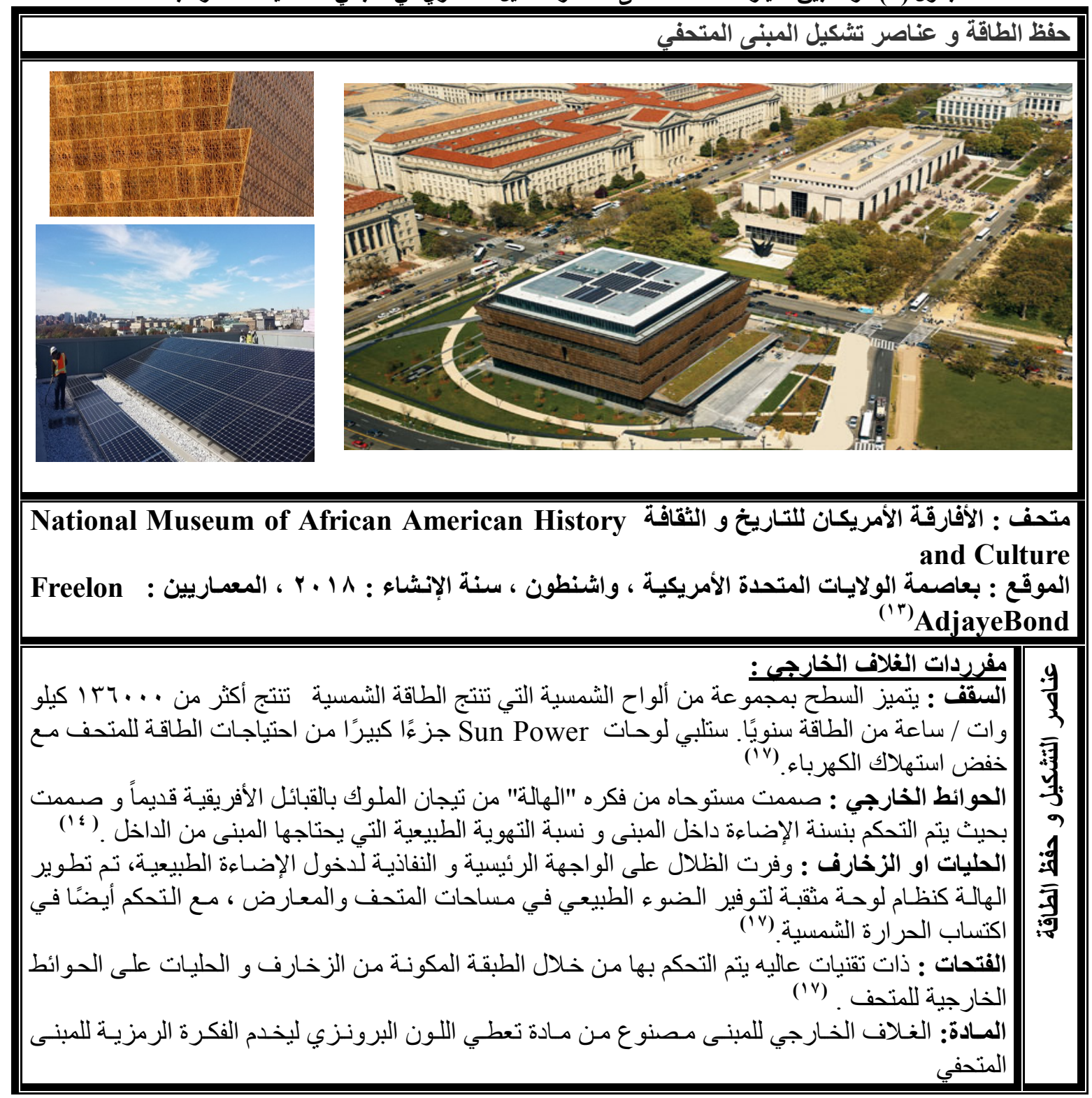

ـ ــ معيار الحفاظ على المواد و الموارد علي عناصر تثكيل المباني المتحفية :

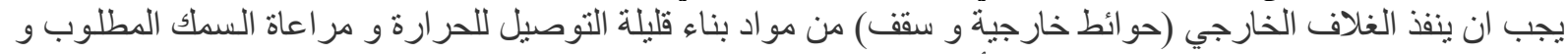

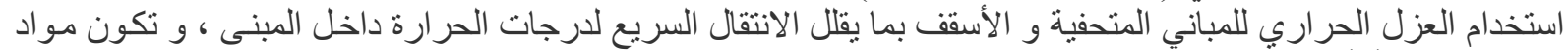

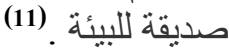

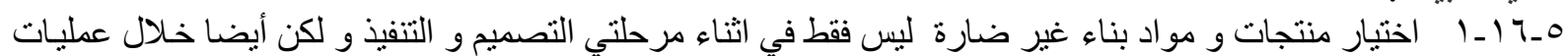

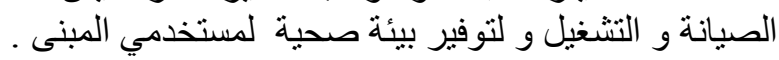




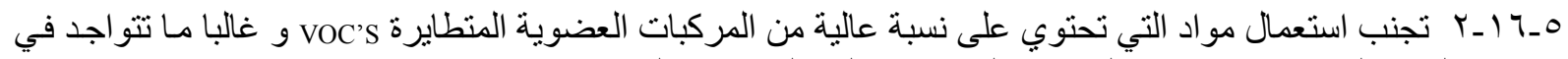

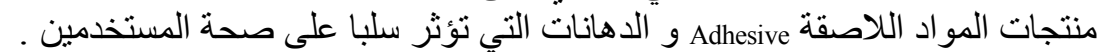

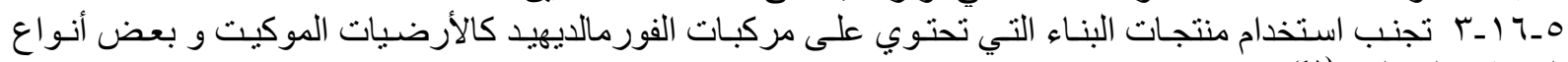
القو اطيع الداخلية . (1)

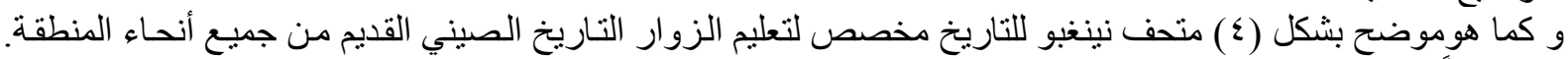

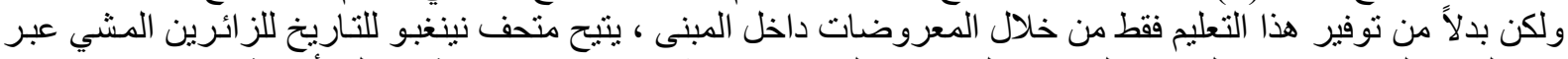

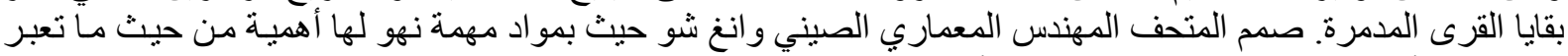

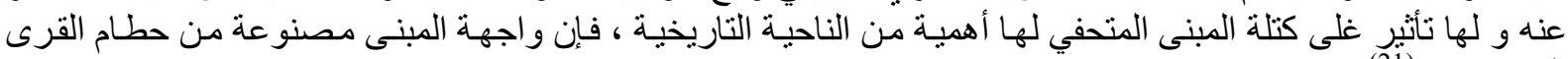
التي دمرت (21)

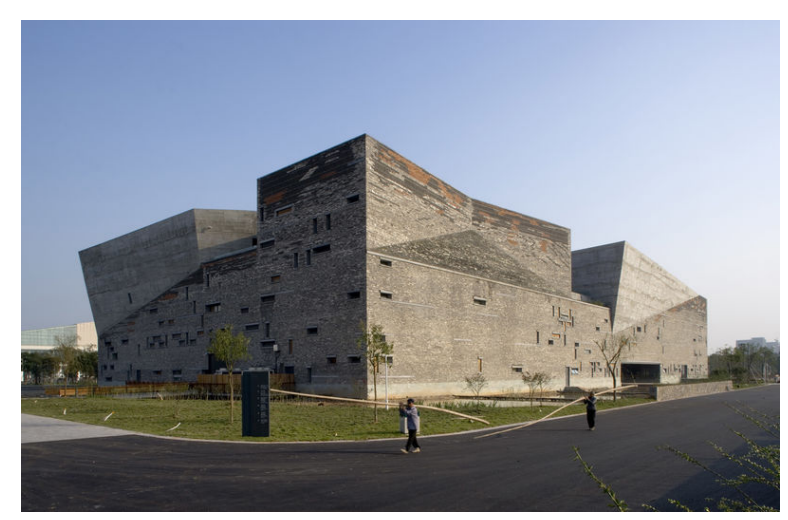

شكل (؛) متحف نينغو للتاريخ بالصين إن واجهة المبنى مصنوعة من حطام القرى التي دمرت عندما

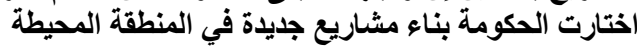

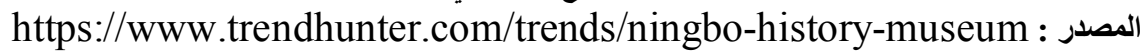

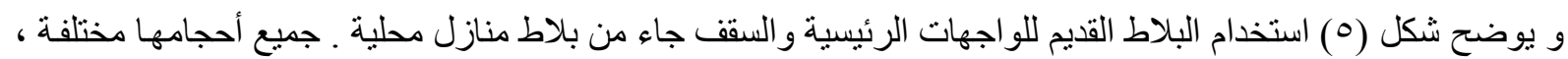

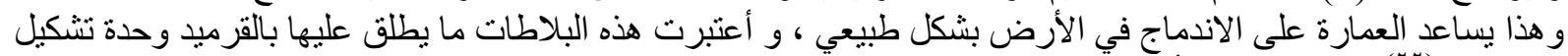

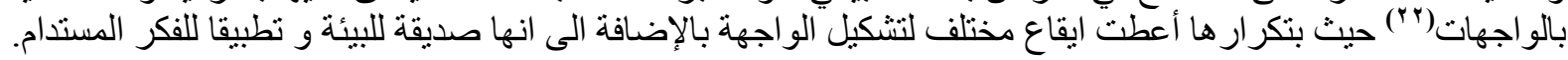

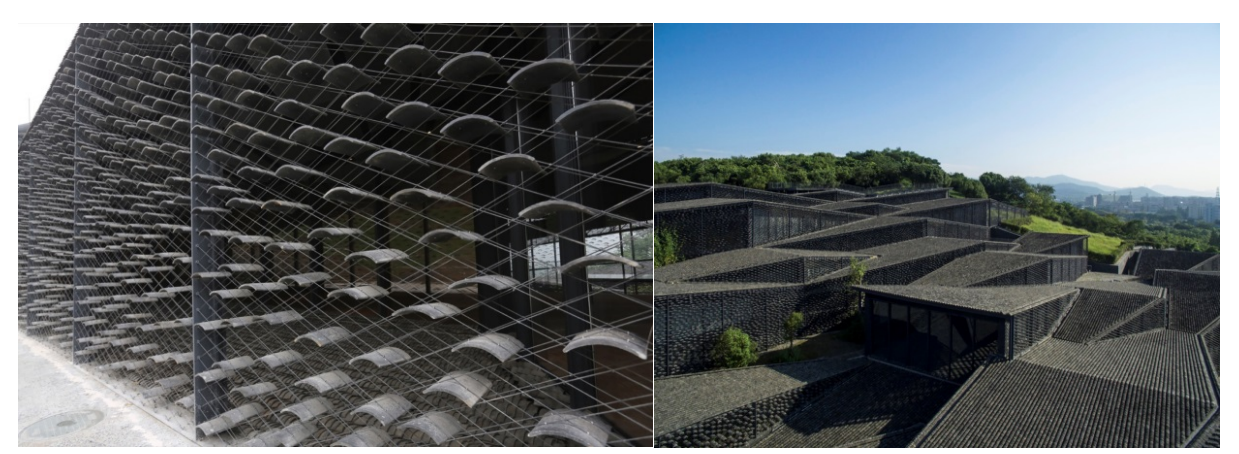

شكل (0) متحف الفنون الثعبية التابع لأكاديمية الصين للفنون

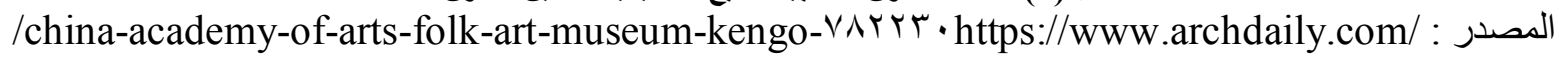
kuma-and-associates

ـ ـه الاستعمال الأكفاء لمصدر المياه و تثنكيل المبني المتحفي:

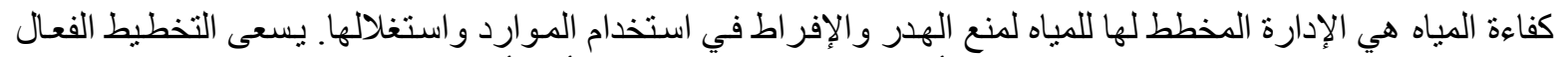

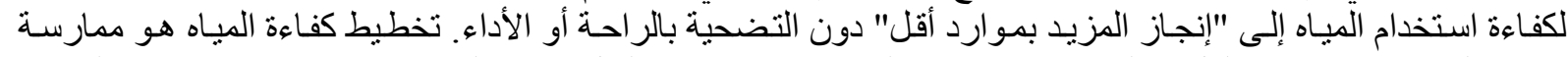

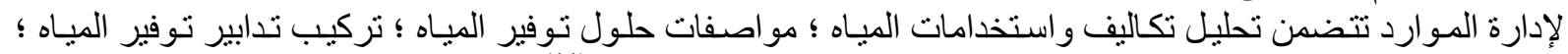

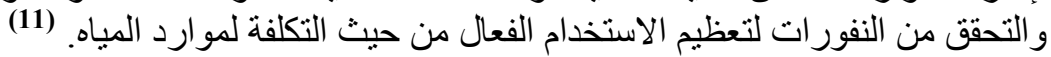




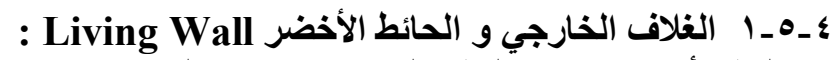

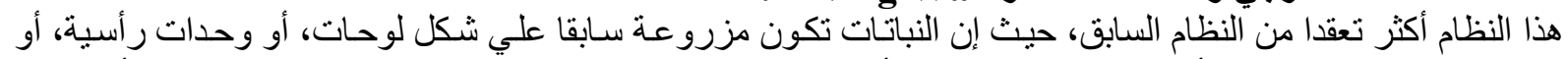

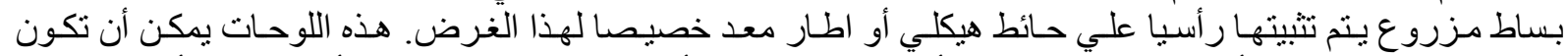

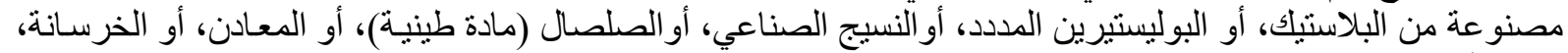

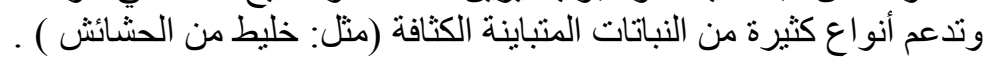

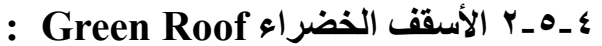

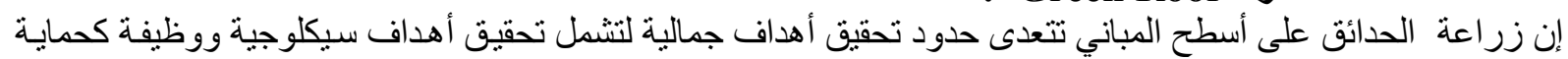

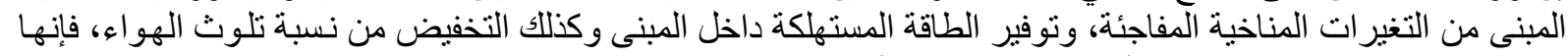

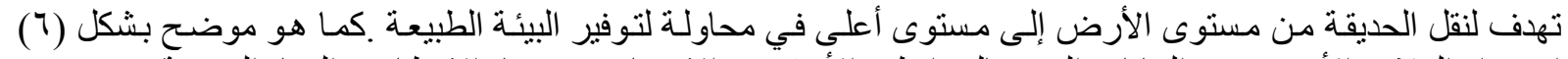

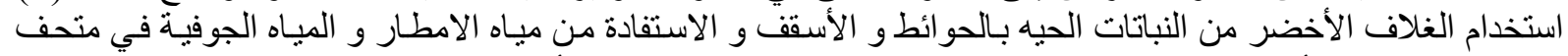

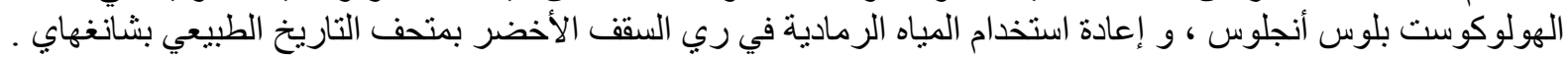

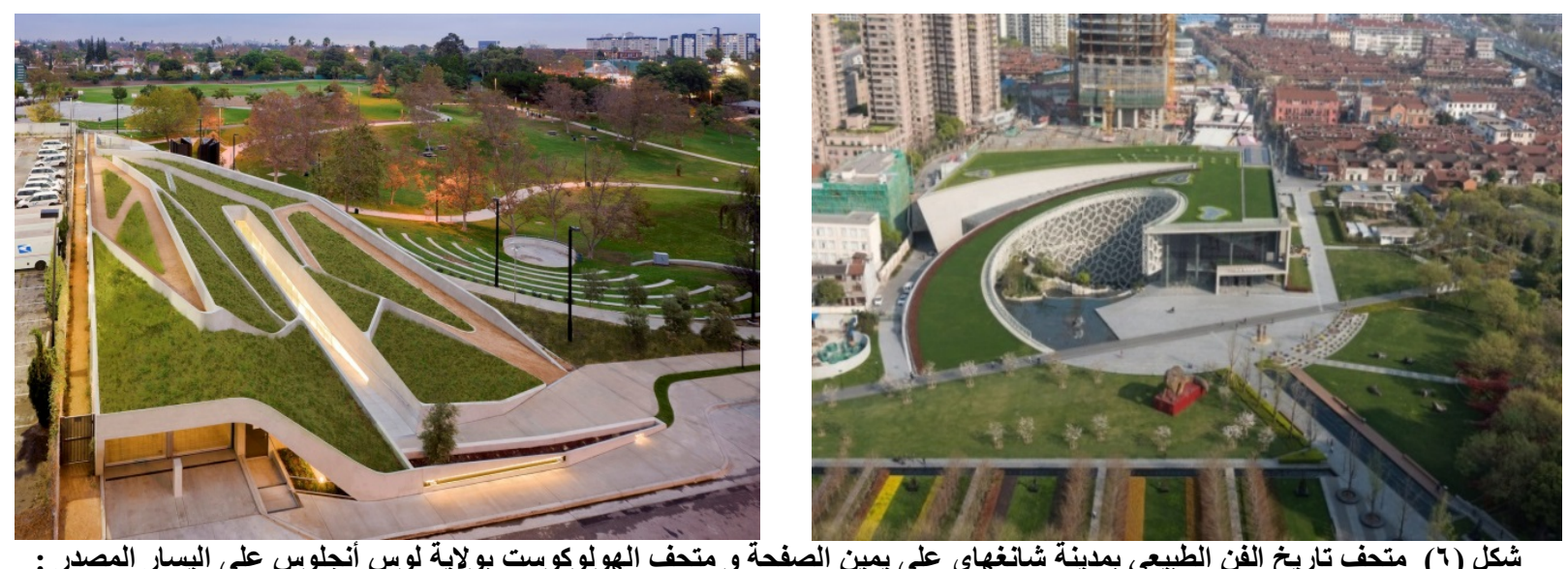
/https://www.syr-res.com/article

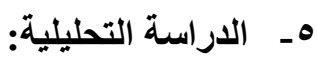

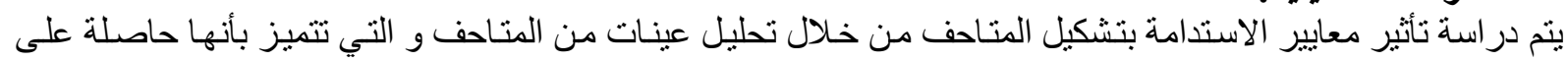

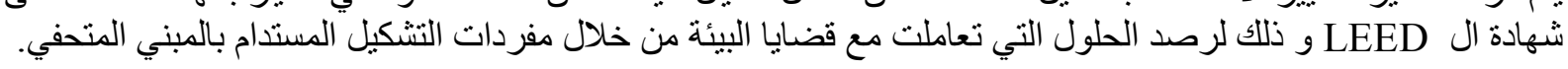

\section{Shanghai Natural History Museum}

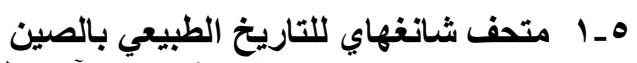

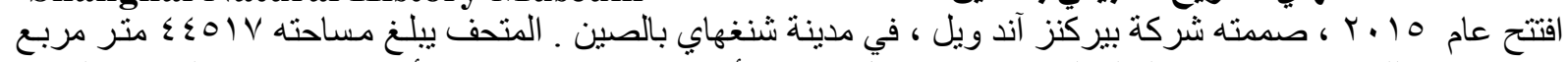

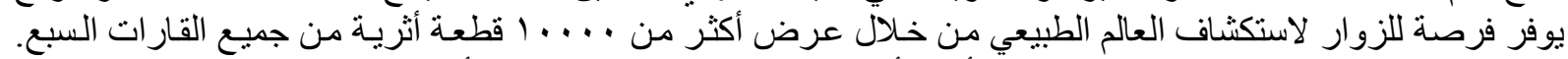

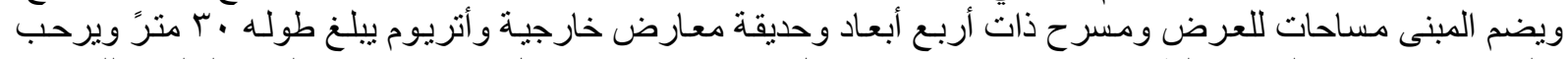

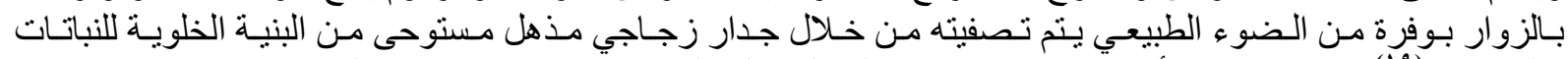

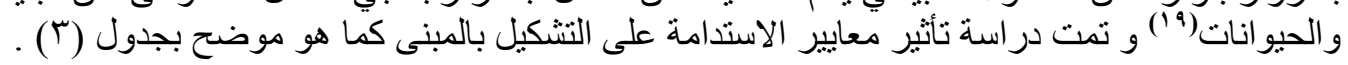




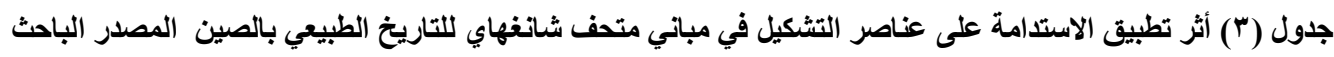

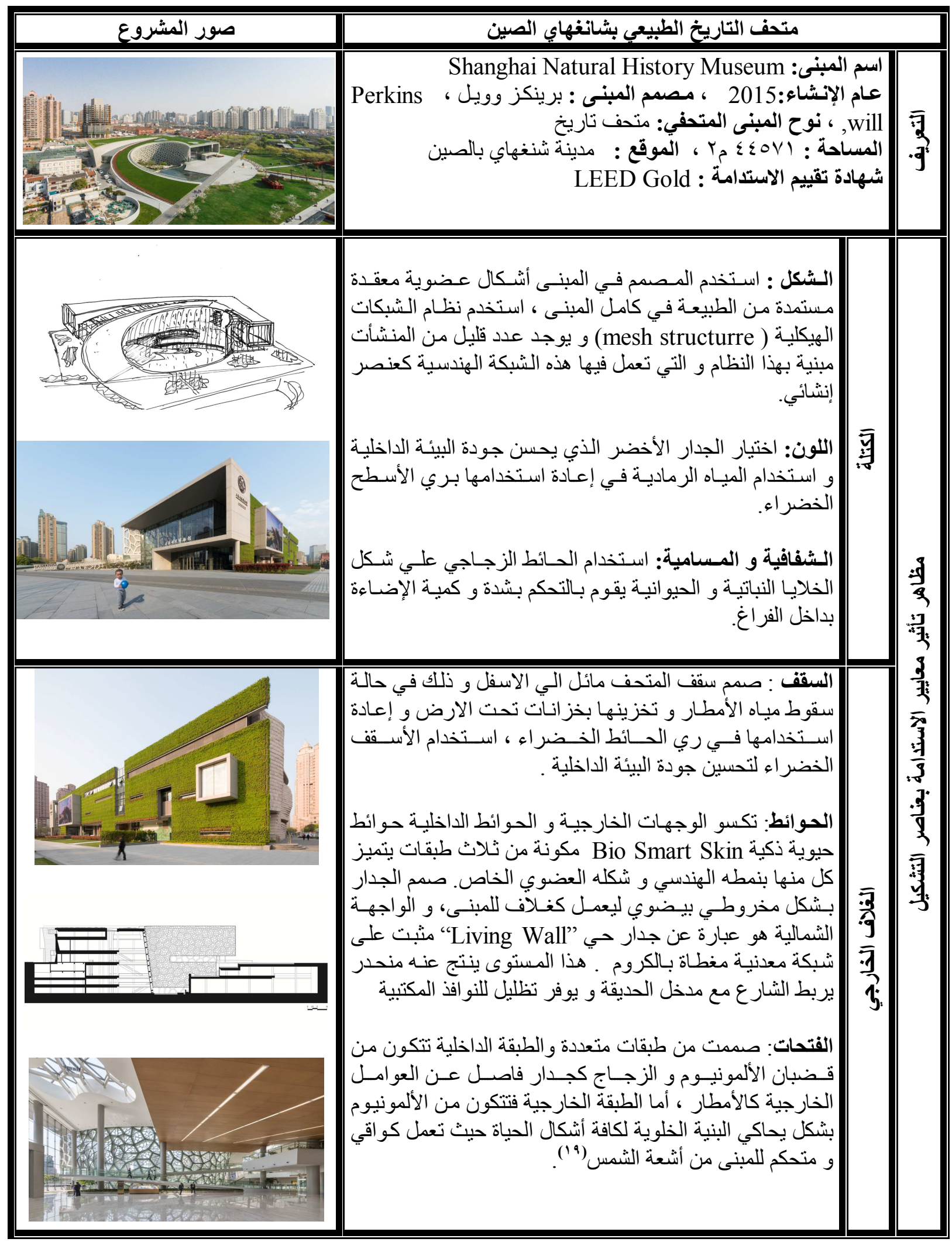




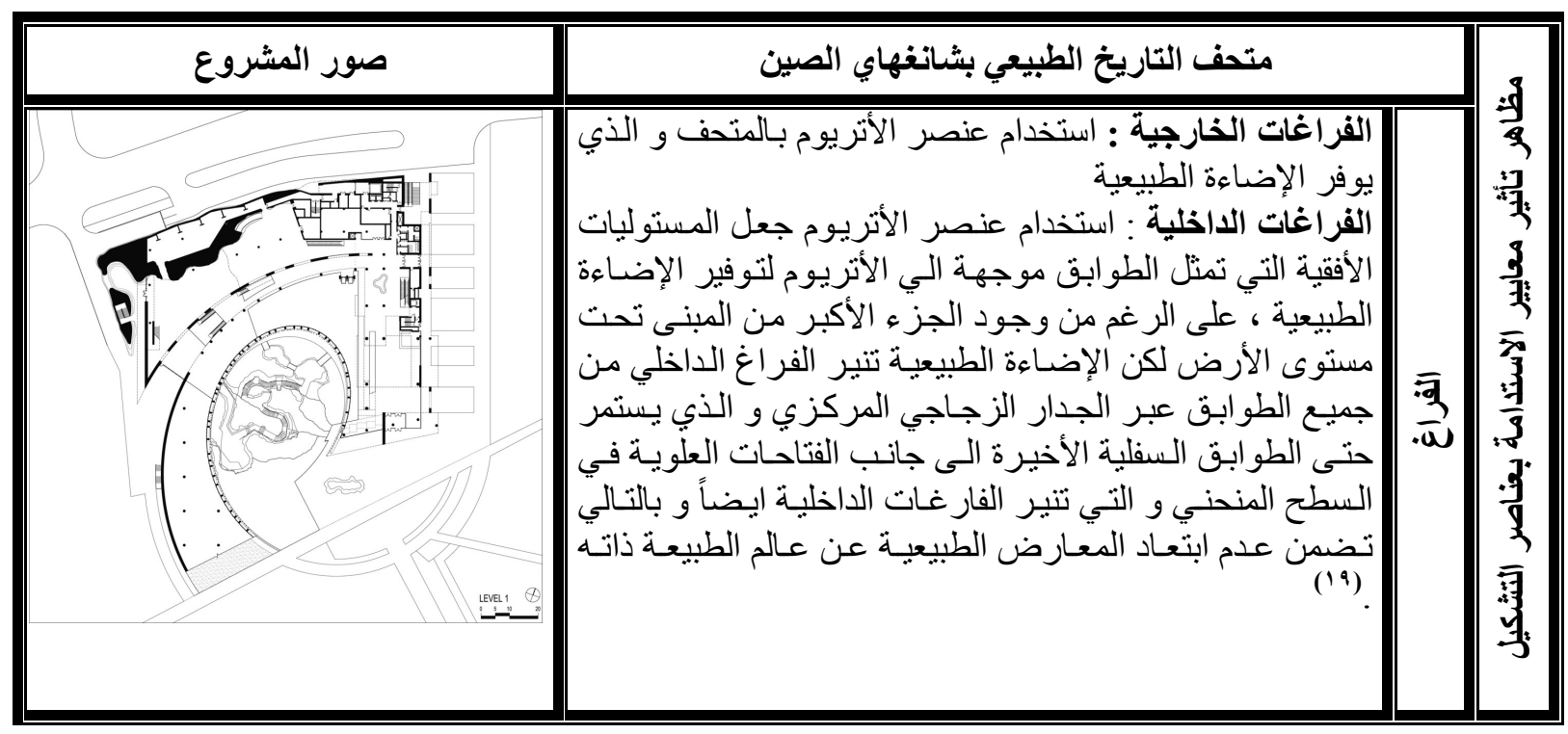

و تم تحليل المبنى المتحفي من خلال نموذج لقياس العلاقة بين التشكيل و الاستدامة في المتاحف و الذي يتكون من •

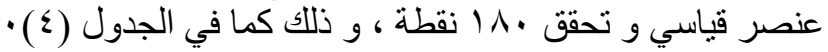

جدول(ء) لتقييم أثر معايير الإستدامة على مفردات التثكيل بالمبنى متحف التاريخ الطبيعي بشانغهاي المصدر الباحث

\begin{tabular}{|c|c|c|c|c|c|c|c|c|c|c|c|c|}
\hline \multicolumn{2}{|c|}{ | الفراغ } & \multicolumn{5}{|c|}{ الغلاف الخارجي } & \multicolumn{4}{|c|}{ الكتلة } & & \\
\hline $\begin{array}{l}\text { 牙 } \\
\bar{n} \\
\bar{j} \\
\bar{j}\end{array}$ & 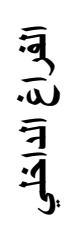 & 寻 & $\begin{array}{l}\frac{y}{3} \\
\frac{\sqrt[n]{3}}{3} \\
\frac{3}{3}\end{array}$ & 事 & 六 & : & 争 & $\overline{3}$ & 宗 & $\begin{array}{l}\text { 矛 } \\
\text { 氛 }\end{array}$ & & \\
\hline & & & & & & & & & & & إستدامة الموقع & \\
\hline & & & & & & & & & & & حفظ الطاقة & 3 \\
\hline & & & & & & & & & & & كفاءة إستخدام المياه & 2 \\
\hline & & & & & & & & & & & كفاءة استخدام المواد و & 8 \\
\hline & & & & & & & & & & & تحسين جودة البيئة الداخلية & \\
\hline
\end{tabular}

تأثيثير قوي =

r

لا يوجد تأثير =

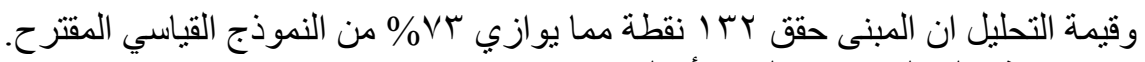

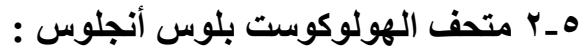

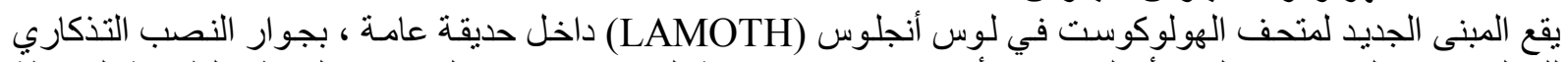

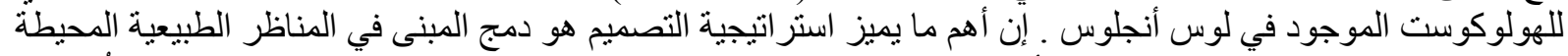

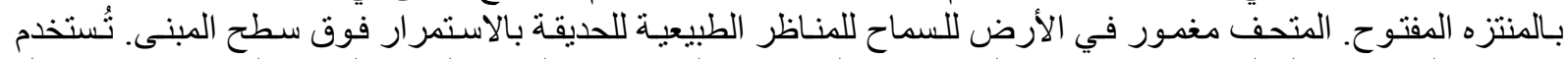

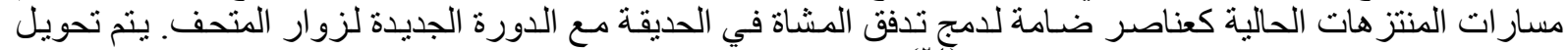

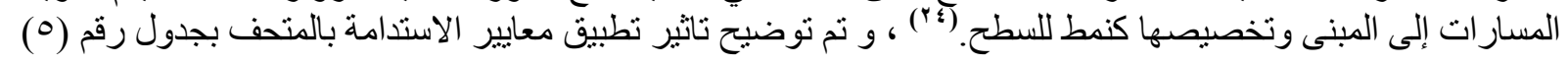


جدول (0) أثر تطبيق الاستدامة على عناصر التثكيل في مباني متحف الهولوكوست بلوس أنجلوس بالولايات المتحدة الأمريكية المصدر الباحث

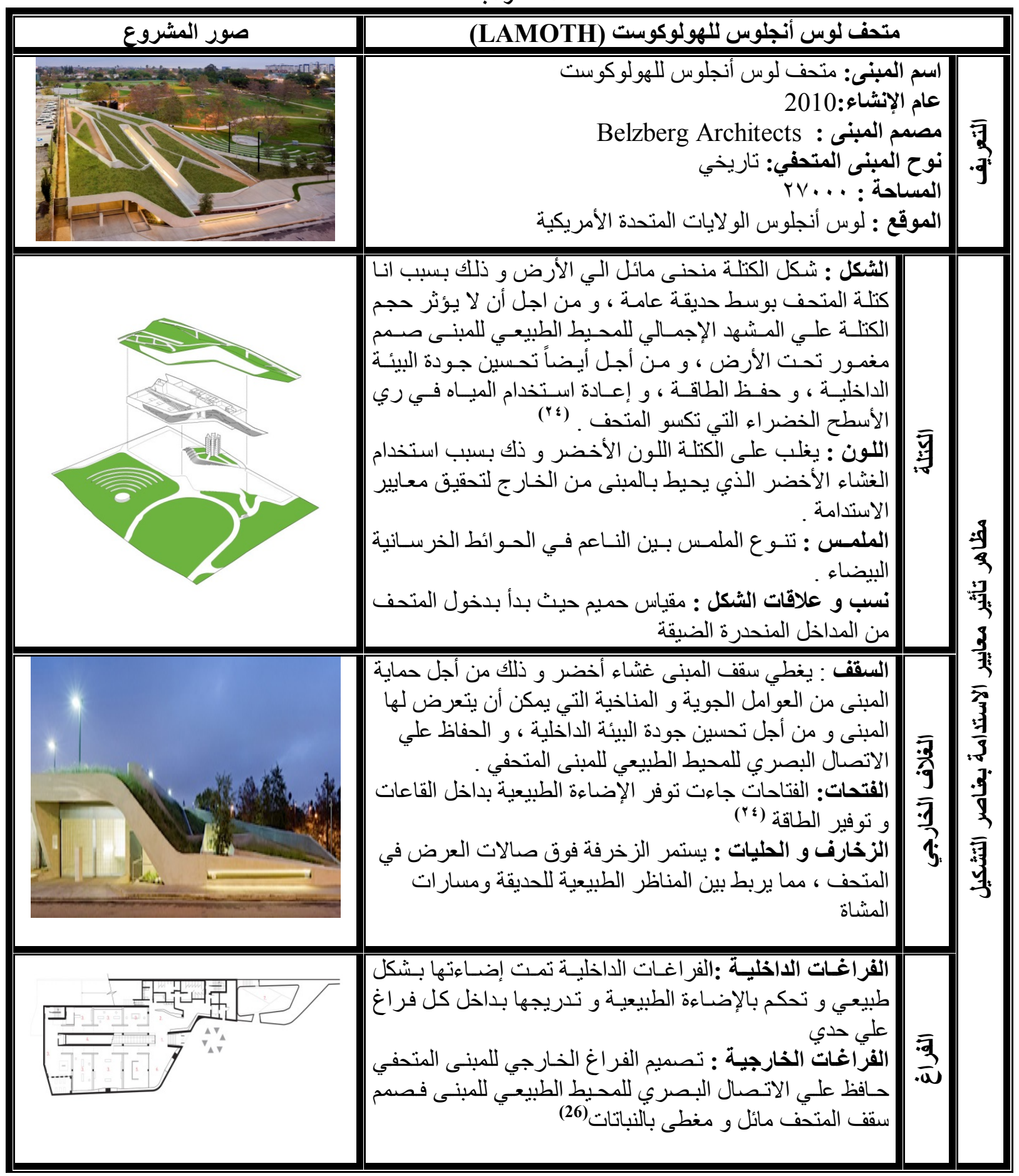

نموذج لتقييم أثر معايير الإستدامة علي عناصر التثكيل بمتحف التاريخ الطبيعي شانغهاي : 
ENHANCEMENT OF CONCRETE PROPERTIES AND STRUCTURAL SYSTEM FOR TELECOMMUNICATION MANHOLE COVERS

جدول(†) لتقييم أثر معايير الاستدامة على مفردات التشكيل بالمبنى متحف التاريخ الطبيعي بشانغهاي المصدر الباحث

\begin{tabular}{|c|c|c|c|c|c|c|c|c|c|c|c|c|}
\hline إغ & & & رجي & 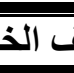 & & & & الكتلة & & & & \\
\hline 哥 & 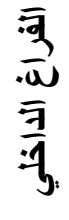 & 武: & $\begin{array}{l}\frac{1}{3} \\
\frac{1}{3} \\
3 \\
3 \\
3\end{array}$ & 牙 & $\frac{\bar{a}}{\bar{y}}$ & 牙 & 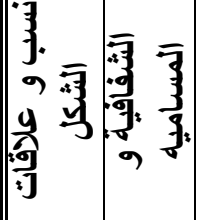 & $\overline{\overline{3}}$ & 可 & 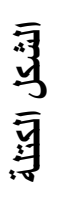 & & \\
\hline & & & & & & & & & & & استدامة الموقع & \\
\hline & & & & & & & & & & & حفظ الطاقة & \\
\hline & & & & & & & & & & & كفاءة استخدام المياه & \\
\hline & & & & & & & & & & & كفاءة استخدام الموادو & \\
\hline & & & & & & & & & & & تحسين جودة البيئة الداخلية & \\
\hline
\end{tabular}

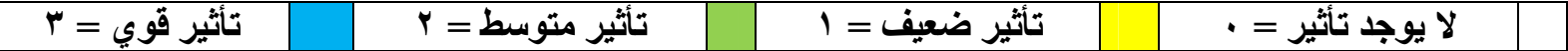

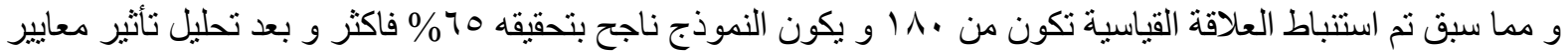

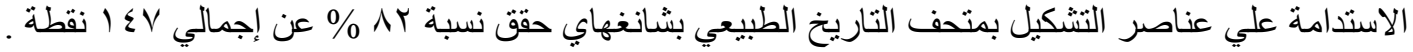

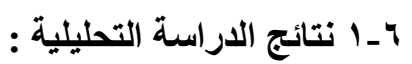

1 - اثبات أن هنالك علاقة قوية بين التشكيل و الاستدامة في المتاحف و التي ثنتت من خلال تطبيق النموذج القياسي و

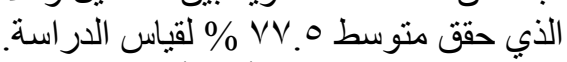

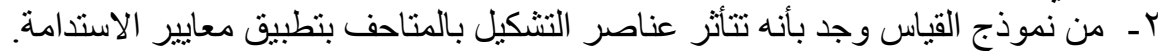

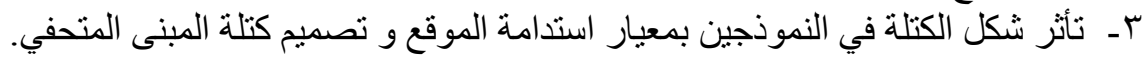

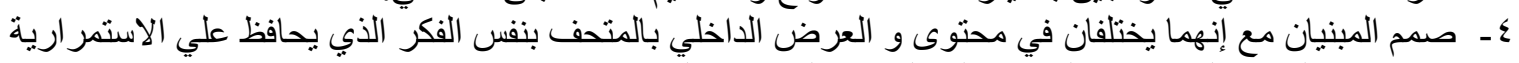

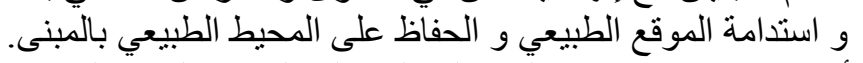

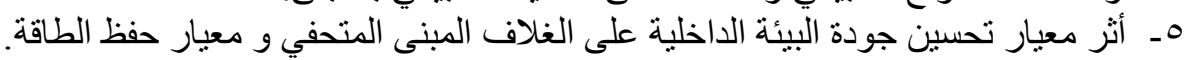

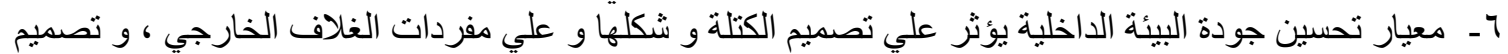

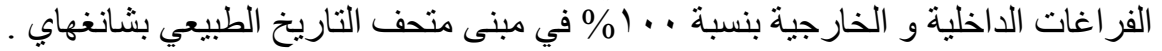

$$
\text { و موضح ذلك بشكل رقم (V). (^) }
$$


ENHANCEMENT OF CONCRETE PROPERTIES AND STRUCTURAL SYSTEMFOR TELECOMMUNICATION MANHOLE COVERS

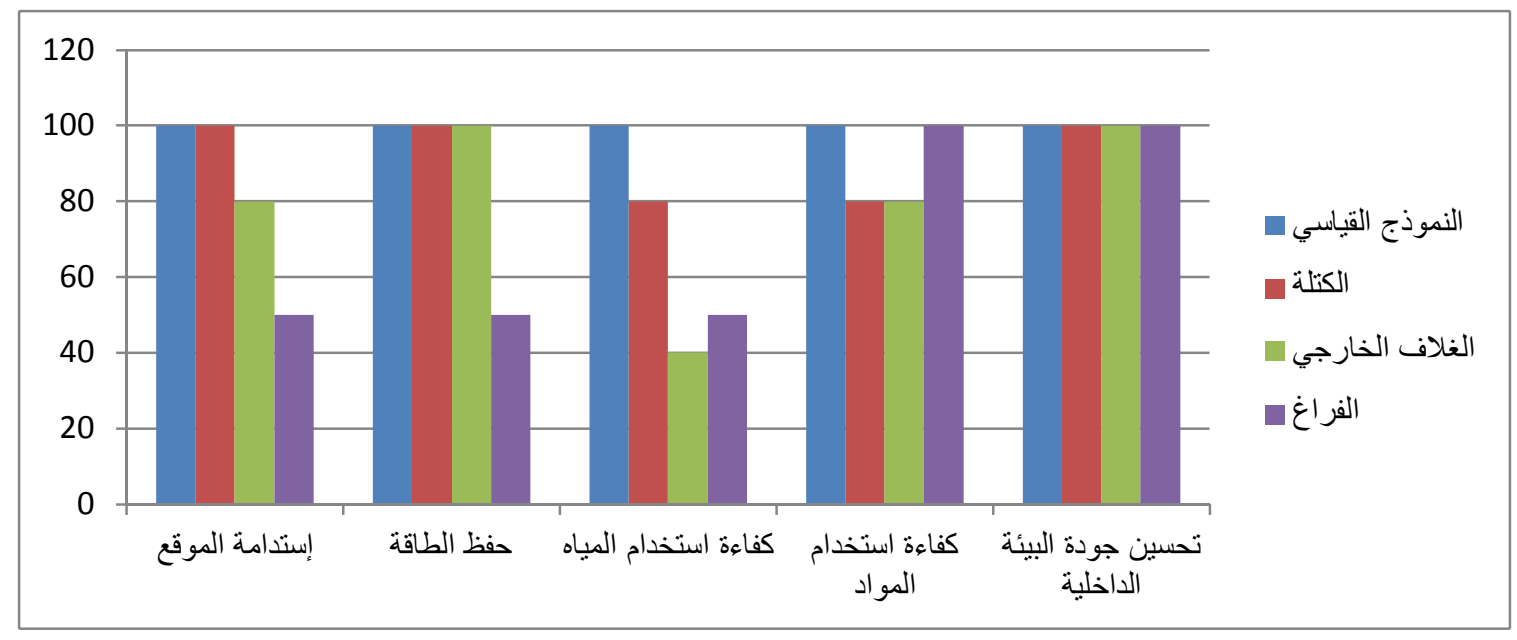

شكل (V) يوضح تأثير معايير الإستدامة بعناصر التثكيل بمتحف الهولوكوست بلوس أنجلوس المصدر (الباحث)

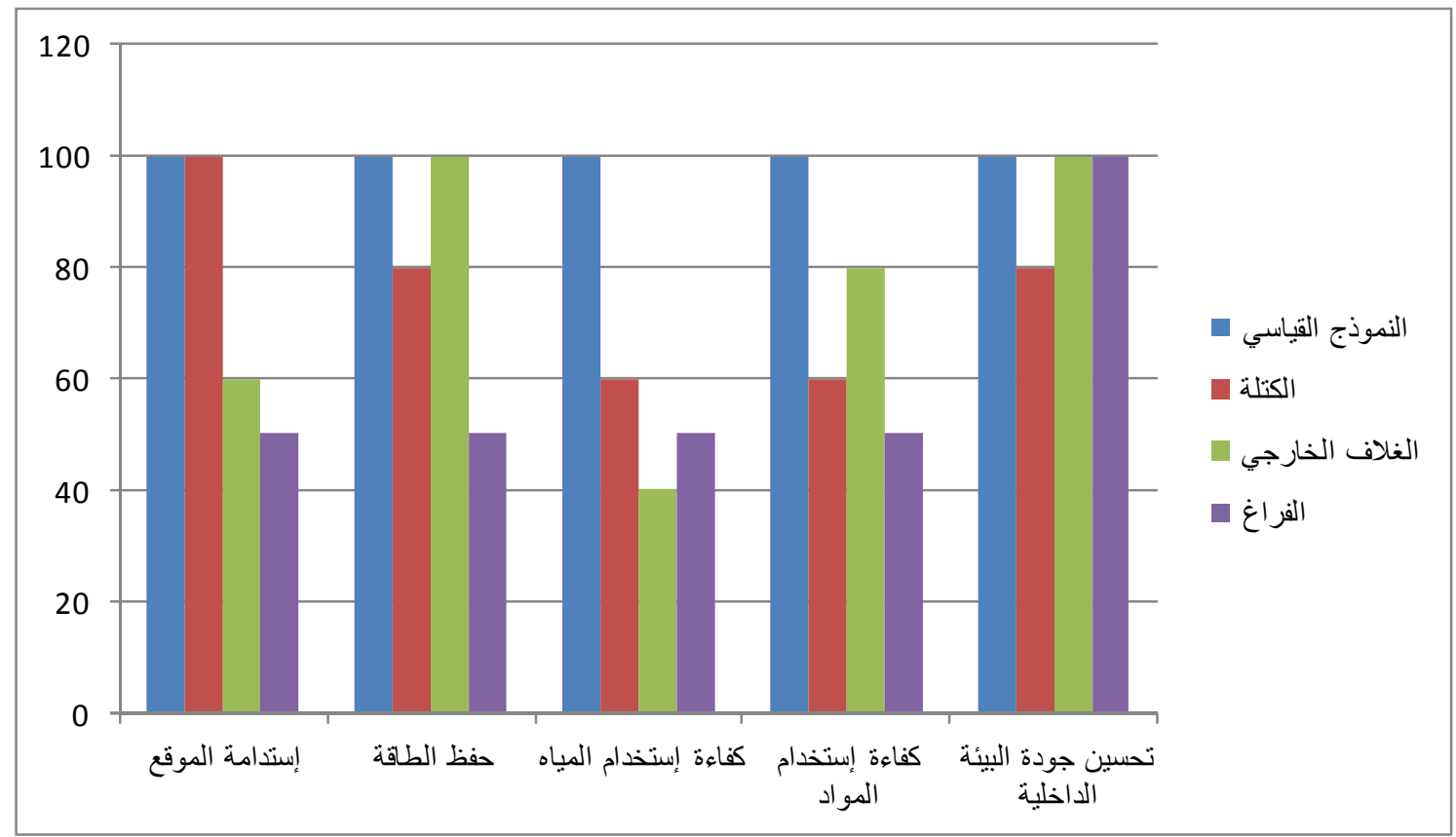

شكل (^) يوضح تأثير معايير الاستدامة بعناصر التثكيل بمتحف التاريخ الطبيعي بثانغهاي الصين المصدر (الباحث) 


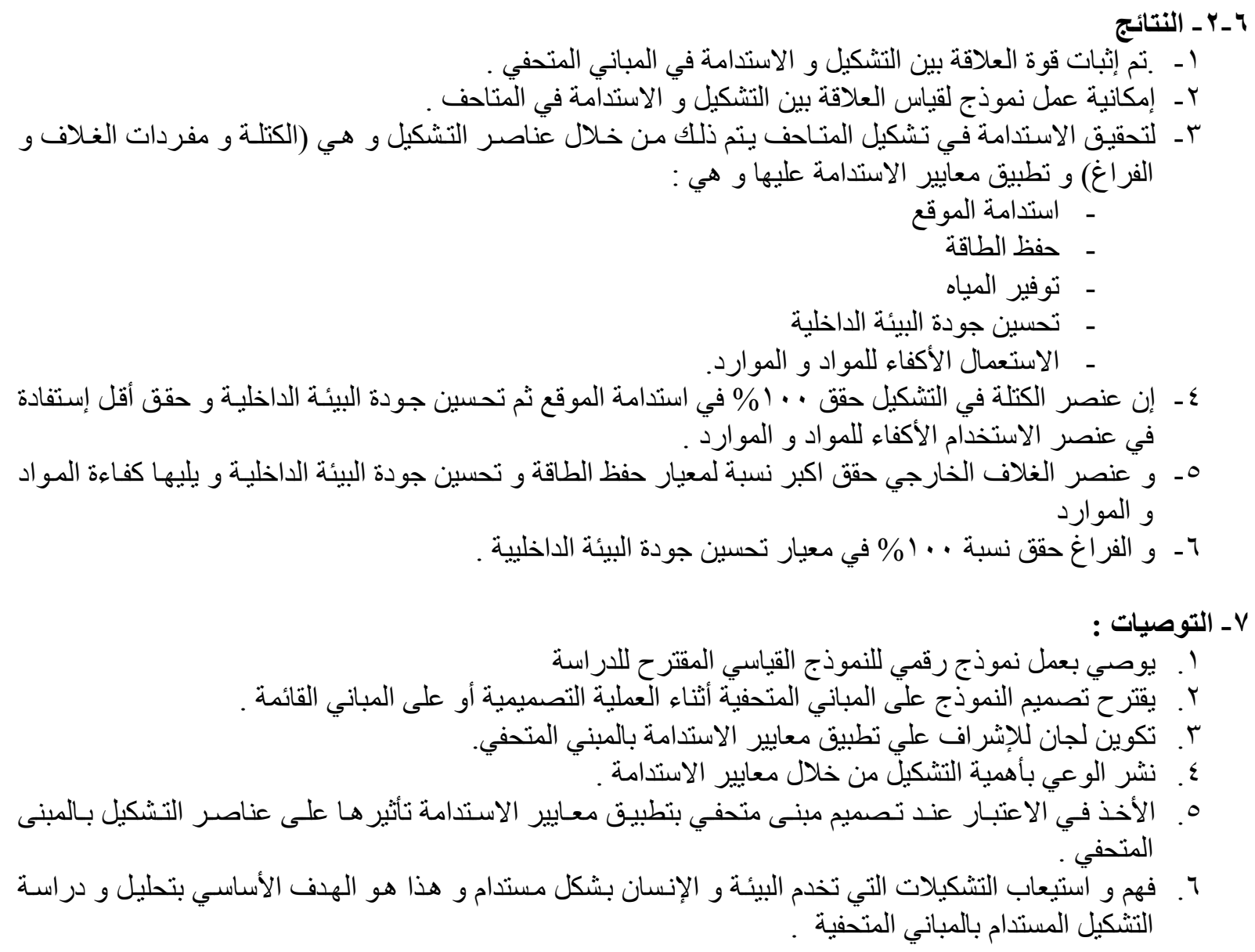

8. Ashrae Handbook Heating(2015), Ventilating, And Air-Conditioning APPLICATIONS Ch.23 P.23.

9. Sutter,G.c(2006).Thinking like a system : Are museums up to the challenge ? Museums and social issues,vol1,no.2, fall 2006, pp203-218

10. Wylie, E. \& Brophy, S.S. (2008). The greener good: The enviro-active museum January/February 2008.

11. Museums And Sustainability Guidelines (2003) for policy and practice in museums and galleries $2003 \mathrm{p} 7$

12. Stylianou-Lambert, T.; Boukas, N.; Christodoulou-Yerali,(2014) M. Museums and cultural sustainability : Stakeholders, forces, and cultural policies. Int. J. Cult. Policy, p20, $566-587$.

13. Case Study National Museum of African American History \& Culture https://www.usgbc.org/resources/case-study-national-museum-african-american-historyculture 
14. Kimmelman, Michael (2016 ,Sept. 21), David Adjaye on Designing a Museum That Speaks a Different Language

15. A practical Guide for sustainable climate control and lighting in Museums \& Galleries (2013)

16. Skluzacek . Catherine R. (2010), Universality and its Discontents: the Louvre and Guggenheim Abu Dhabi as a Case Study in the Future of Museums, Macalester Colleg

17. Sustainable design at national museum Of African American History and culture https://buildingos.com/s/smithsonian/NMAAHC/?chapterId=291

18. Imbert . Frédéric , Frost Kathryn Stutts , (2010)Concurrent Geometric, Structural and Environmental Design, Louvre Abu Dhabi

19. L.(luyuan) Li , (2009, August ), Cellular Wall Design With Parametric CAD Models p20,p21,p22

20. Lindsay Georgia (2020, january), Contemporary Museum Architecture and Design: Theory and Practice of Place, p2:18

21. Vladimir J. Konečni (2015,july,31), Two Extraordinary New Museums in South-Eastern China, s. http://www.scirp.org/journal/adr

22. Iryna BONDARENKO, Zhaohui WANG (2020, February) The selected architectural solution of modern museums in china in the aspect of manifestation of traditional culture p19,20,21

23. Jerry Yudelson,(2007)" Green Building A to Z Understanding the Language of Green Building", New Society Publishers, Canada, p164-165.

24. Chang, Wenxin, Gao, Wei (2011), Thematic Museum ,p12,19

25. Pop, Izabela Luiza (2019,Febrauary), Achieving Cultural Sustainability in Museums: A Step Toward Sustainable Development ,p15

26. Los Angeles Museum of the Holocaust, Belzberg Architects,(2014,janaury) https://www.archdaily.com/467894/los-angeles-museum-of-the-holocaust-belzberg-architects 